San Jose State University

SJSU ScholarWorks

Master's Theses

Master's Theses and Graduate Research

1995

\title{
The ability of individuals with schizophrenia to estimate task performance
}

Jennifer Claire Chapman

San Jose State University

Follow this and additional works at: https://scholarworks.sjsu.edu/etd_theses

\section{Recommended Citation}

Chapman, Jennifer Claire, "The ability of individuals with schizophrenia to estimate task performance" (1995). Master's Theses. 1052.

DOI: https://doi.org/10.31979/etd.4yr2-4425

https://scholarworks.sjsu.edu/etd_theses/1052

This Thesis is brought to you for free and open access by the Master's Theses and Graduate Research at SJSU ScholarWorks. It has been accepted for inclusion in Master's Theses by an authorized administrator of SJSU ScholarWorks. For more information, please contact scholarworks@sjsu.edu. 


\section{INFORMATION TO USERS}

This manuscript has been reproduced from the microfilm master. UMI films the text directly from the original or copy submitted. Thus, some thesis and dissertation copies are in typewriter face, while others may be from any type of computer printer.

The quality of this reproduction is dependent upon the quality of the copy submitted. Broken or indistinct print, colored or poor quality illustrations and photographs, print bleedthrough, substandard margins, and improper alignment can adversely affect reproduction.

In the unlikely event that the author did not send UMI a complete manuscript and there are missing pages, these will be noted. Also, if unauthorized copyright material had to be removed, a note will indicate the deletion.

Oversize materials (e.g., maps, drawings, charts) are reproduced by sectioning the original, beginning at the upper left-hand comer and contimuing from left to right in equal sections with small overlaps. Each original is also photographed in one exposure and is included in reduced form at the back of the book.

Photographs included in the original mamuscript have been reproduced xerographically in this copy. Higher quality $6^{n} \times 9^{n}$ black and white photographic prints are available for any photographs or illustrations appearing in this copy for an additional charge. Contact UMI directly to order.

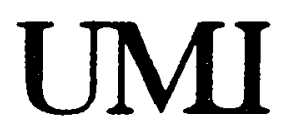

A Bell \& Howell information Company 300 North Zeeb Road. Ann Arbor. M1 48106-1346 USA 313:761-4700 800:521-0600 


-




\title{
THE ABILITY OF INDIVIDUALS WITH SCHIZOPHRENIA TO ESTIMATE TASK PERFORMANCE
}

\author{
A Thesis \\ Presented to \\ The Facutly of the Department of Occupational Therapy \\ San Jose State University
}

In Partial Fulfillment

of the Requirements for the Degree

Master of Science

By

Jennifer Claire Chapman

August, 1995 
UMI Number : 1375676

UMI Microform 1375676

Copyright 1995, by UMI Company. All rights reserved.

This microform edition is protected against unauthorized copying under Title 17, United states code.

\section{UMI}

300 North Zeeb Road

Ann Arbor, MI 48103 
Copyright 1995

Jennifer Claire Chapman

ALL RIGHTS RESERVED 
APPROVED FOR THE DEPARTMENT OF OCCUPATIONAL THERAPY

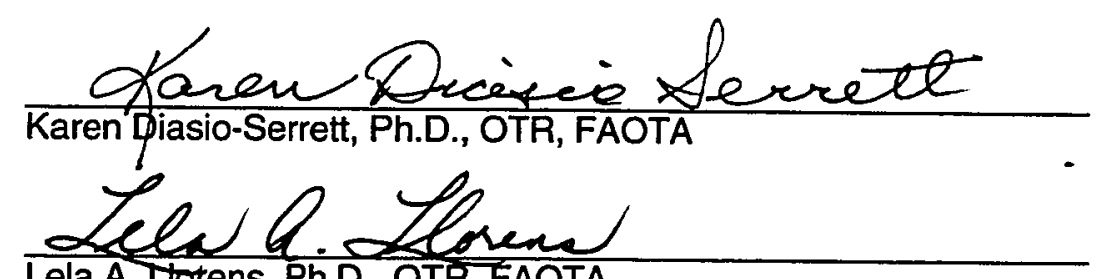
Lela A. Utotens, Ph.D., OTR, FAOTA

Gan Toglia $7 / 3 / 95$

Joan P.Toglia, MS, OTR

APPROVED FOR THE UNIVERSITY

H. Iru Newandourke. 


\title{
ABSTRACT \\ THE ABILITY OF INDIVIDUALS WITH SCHIZOPHRENIA TO ESTIMATE TASK PERFORMANCE
}

\author{
by Jennifer C. Chapman
}

Individuals with schizophrenia exhibit inefficient problem-solving skills. Many factors contribute to cognitive function. Metacognition refers to knowledge of one's own cognitive processes and is integral to one's ability to solve problems. The ability of individuals with schizophrenia to evaluate task difficulty was the focus of this research study. A questionnaire was distributed to twenty outpatient, male and female psychiatric patients.

The research questions were (1) To what degree are individuals with schizophrenia able to estimate their performance Pre - Task? (2) If Pre - Task estimations differ from their task performance, do individuals with schizophrenia overestimate or underestimate their abilities? and (3) To what degree are individuals with schizophrenia able to estimate their performance Post - Task?

Study results showed that individuals with schizophrenia are inaccurate at estimating both Pre - Task and Post - Task performance. Pre - Task estimations compared with observed task performance found respondents to underestimate their abilities. Post - Task estimations compared with task performance found respondents to overestimate their abilities. 


\section{ACKNOWLEDGMENTS}

I wish to express my appreciation for all of the support and encouragement my friends, family, and professors have given me in the process of completing this thesis. I particularly want to thank the occupational therapy staff and patients at CPC Heritage Oaks Hospital for their support.

My thanks to my advisor and readers, Karen Diasio Serrett, Ph.D., OTR, FAOTA, Lela Llorens, Ph.D., OTR, FAOTA, and Joan Toglia, MS, OTR. Special thanks to my husband, Leonard B. Desmul II, MD., for all of your assistance and support. You're the best. 


\section{TABLE OF CONTENTS}

Page

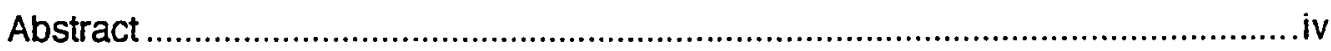

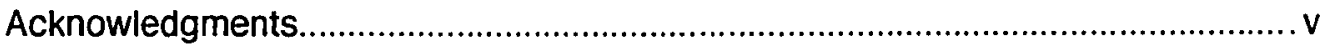

Chapter

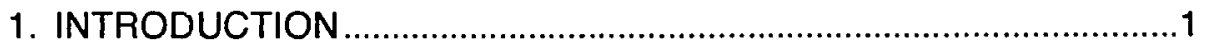

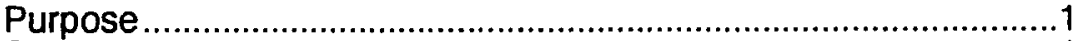

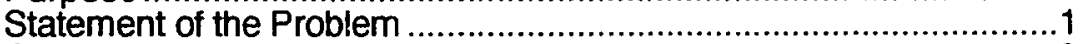

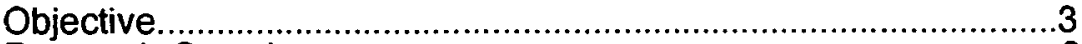

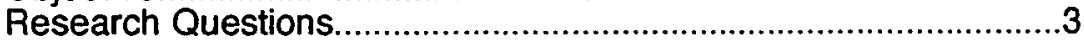

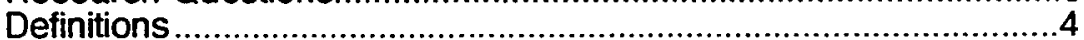

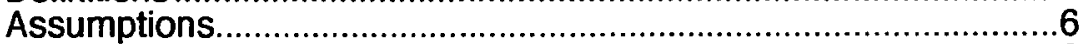

Limitations....................................................................................6

Significance of the Study...............................................................

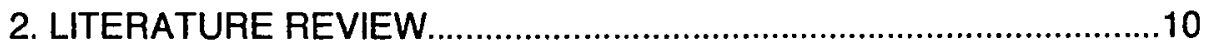

Deficit-Specific Compared With the Dynamic Interactional Approach to Cognitive Rehabilitation........................................10 Cognitive Research on Individuals With Schizophrenia ..................19 Cognitive Research on Brain Injured Individuals ..........................20

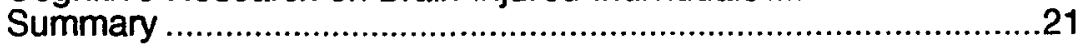

3. DESIGN AND METHODOLOGY …………………….....................23

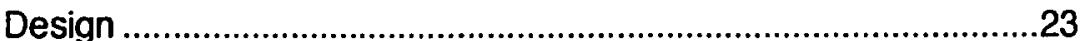

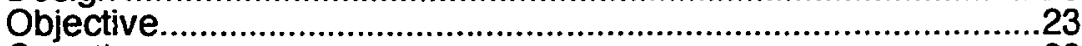

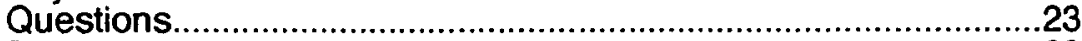

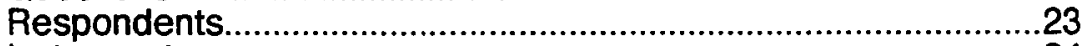

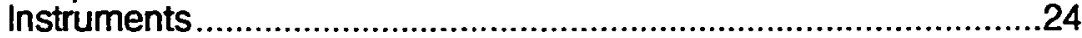

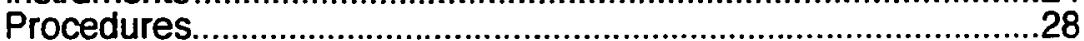

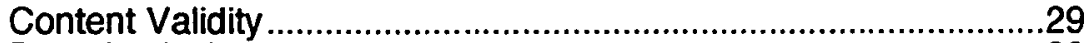

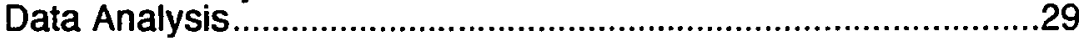

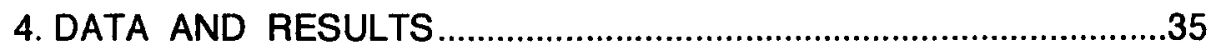

Organization of Chapter............................................................35

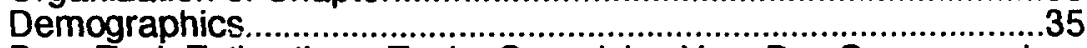

Pre - Task Estimations, Task: Organizing Your Day Scores, and

Post - Task Estimations..............................................................36

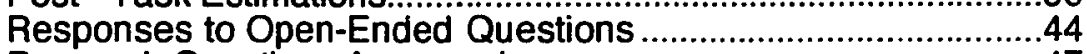

Research Questions Answered ................................................47 
5. SUMMARY AND RECOMMENDATIONS ...........................50

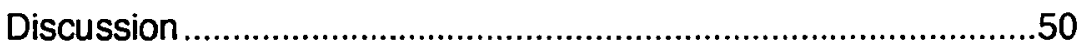

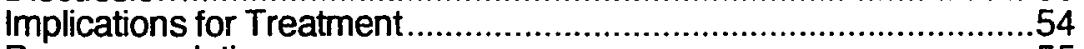

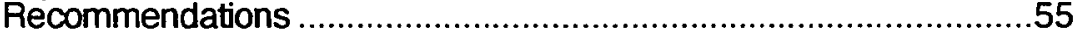

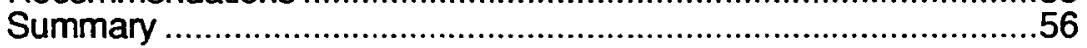

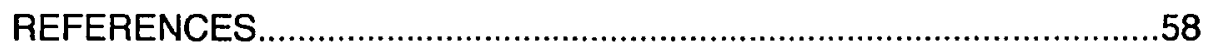

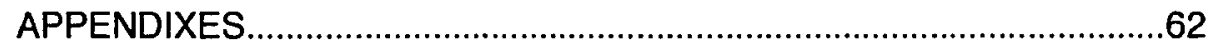

APPENDIX A-Organizing Your Day ..............................................62

APPENDIX B-Pre - Task Questionnaire ......................................64

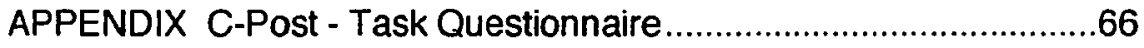

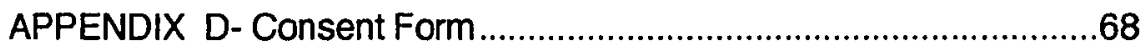

APPENDIX E-Facility Consent For Participation................................70

APPENDIX F-Toglia's Original Organizing Your Day..........................72

APPENDIX G-Organizing Your Day Schedule and Worksheet...........74 


\section{LIST OF TABLES}

\section{TABLE}

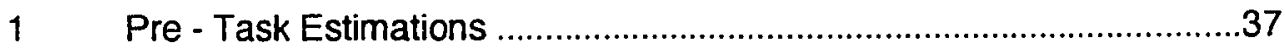

2 Demonstrated Performance Scores on the Task: Organizing Your Day.38

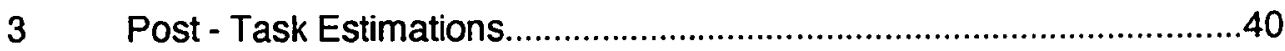

4 Comparison of Pre-Task Estimations and Demonstrated

Performance Scores on the Task: Organizing Your Day........................41

$5 \quad$ Mean Attribution Scores for Pre - Task Estimations Compared to

Demonstrated Scores on the Task: Organizing Your Day ....................43

6 Comparison of Demonstrated Task Performance and

Post - Task Estimations.................................................................45

7 Comparison of Pre - Task Estimations and

Post - Task Estimations to Demonstrated Task Performance.................49 


\section{CHAPTER 1}

\section{INTRODUCTION}

\section{Purpose}

The purpose of this research was to describe the relationship between the selfreported perceptions of a sample of individuals with schizophrenia regarding their ability to evaluate task difficulty and their task performance.

There is a need to expand the knowledge base shared by occupational therapists regarding the underlying processing deficits that contribute to poor task problem-solving ability in individuals with schizophrenia (Bellack, Morrison, \& Mueser, 1989, Toglia \& Fine 1990). The emergence of data describing the underlying processing deficits that contribute to poor problem-solying in persons with schizophrenia is essential to broaden the vision of mental health practice in occupational therapy. Research in this area was conducted that will assist clinicians to better understand the variety of steps involved in problem-solving, and thus foster the development of more effective treatment planning to correct specific deficits in individuals with schizophrenia.

\section{Statement of the Problem}

Individuals with schizophrenia have been shown to have deficits in many of the cognitive operations needed for problem-solving, specifically informatior: processing (Penn, Van Der Does, Spaulding, Garbin, Linszen, \& Dingemans, 1993). A person needs to process information before solving a problem. A disturbance of cognitive or perceptual skills has a detrimental effect on a person's ability to function independently and perform life roles. The individual with schizophrenia often demonstrates poverty of roles, nonproductive habits and inefficient routines (Depoy \& Kolodner in Christiansen \& Baum, 195?). An individual who exhibits poor problem-solving skills may be unable to prioritize 
the steps to proceed in a stepwise progression or may be unable to break the task into steps. Excessive time may be spent processing nonessential details. Cognitive dysfunction can affect functioning in all areas of social, work, leisure, and daily living. Characteristic rigidity of thought, as observed in individuals with schizophrenia, results in a limited ability to devise alternative solutions to problems (Toglia \& Golisz, 1990). This helps to explain why the primary role of an individual with schizophrenia is that of dependent, chronic patient (Depoy \& Kolodner in Christiansen \& Baum, 1992; Duchek in Christiansen \& Baum, 1992). Thus, cognitive dysfunction has a significant impact on role performance and overall adaptive potential (Fine, 1992).

The presence of measurable cognitive and perceptual impairment has been well documented in individuals with schizophrenia (Fine, 1992). Additionally, individuals with schizophrenia have been shown to exhibit inefficient or non-existent problem-solving skills in their daily lives. One who does not understand his or her true cognitive capacities and limitations may be unwilling or unable to employ a variety of strategies when problem-solving. If that person perceives a task as easy he or she may be less likely to exert effort, use special strategies, or monitor, and verify performance outcome (Toglia in Katz, 1992). Conversely, problem-solving may not proceed if the person feels unable to cope with the situation (Bellack, Morrison, \& Mueser, 1989).

Many interrelated factors contribute to cognitive function, information processing, and leaming. These include: structural capacities, processing strategies, metacognitive processes, and individual characteristics such as knowledge and motivation (Bransford, Sherwood, Vye, \& Reiser, 1986). Metacognitive processes are integral to one's ability to solve problems. Metacognition refers to knowledge and regulation of one's own cognitive processes and capacities (Flavell, 1985).

The skills involved in metacognition include: the ability to assess task difficulty in relation to current skills, plan for future events, choose appropriate strategies, and monitor 
performance (Toglia, 1991). The ability to self-estimate one's own cognitive capacities and evaluate task difficulty in relation to one's current skills is central to effective problemsolving. The dynamic interactional model of cognition assumes that a number of different factors including metacognitive skills, such as awareness and self-monitoring, may influence performance on any cognitive task. The dynamic interactional assessment approach identifies deficiencies in basic processing and self-monitoring skills that affect performance (J. P. Toglia, personal communication, October 15, 1993).

The dynamic interactional model of cognition supplements conventional skillspecific views of dysfunction in addressing underlying conditions, processing strategies, and evaluating environmental situations that influence performance. Although Toglia (1993) has informally used this approach to assess problem-solving deficits with a braininjured population, it has not been studied with a schizophrenic population.

There is currently a paucity of research in this area of study. Presenting data that describe the underlying processing deficits that contribute to poor problem-solving in persons with schizophrenia is essential to broaden the vision of mental health practice in occupational therapy.

\section{Objective}

The objective of this study was to describe the relationship between the selfreported perceptions of a sample of individuals who have a diagnosis of schizophrenia, regarding their ability to evaluate task difficulty and their subsequent observed performance on a cognitive task.

\section{Research Questions}

The research questions generated for the study were:

1) To what degree are individuals with schizophrenia able to estimate their performance Pre - Task?

2) If Pre - Task estimations differ from task performance, do individuals with 
schizophrenia overestimate or underestimate their abilities?

3) To what degree are individuals with schizophrenia able to estimate their performance Post - Task?

\section{Definitions}

\section{Conceptual}

Conceptual definitions used in this study were the following:

Cognition: A person's capacity to acquire and use information to adapt to environmental demands. It encompasses information processing skills, learning, and generalization. Cognition is viewed as dynamic not static; it changes with the individual's interaction with the external world (Lidz, 1987).

Metacognition: The knowledge and regulation of one's personal cognitive processes and capacities (Flavell, 1985).

Metacognitive skills: The ability to evaluate task performance in relationship to current skills, to plan ahead, to choose appropriate strategies, and to predict the consequences of action and monitor performance (Toglia, 1991).

Negative symptoms: Those aspects of schizophrenic disorders characterized by a loss of normal function; lack of thought or roles; affective flattening, alogia (poverty of speech), avolition, anhedonia (difficulties in experiencing interest or pleasure), and attention impairments (Depoy \& Kolodner in Christiansen \& Baum, 1992; Fine, 1992). Perception: The process of consciously recognizing and interpreting sensory stimuli. Perception of performance: The respondents' interpretations of information provided about a task and their reported beliefs about their ability to accomplish that task. Processing strategies: Observable behaviors that are reflective of the input and elaboration of information. Metacognitive skills can influence all stages of information processing, including the ability to solve problems (J. P. Toglia, personal communication, October 15, 1993). 
Schizophrenia: A complex grouping of disorders characterized by psychotic features, such as hallucinations, incoherence, delusions, and symptoms involving such multiple psychological processes as content and form of thought, perception, affect, sense of self, volition, relationship to the extemal world, and psychomotor behavior. Other criteria include deterioration from previous level of functioning, onset before age 45 , and a duration of at least 6 months (American Psychiatric Association, 1986).

\section{Operational}

Operational definitions defined for this study were the following:

Individuals with Schizophrenia: For the purposes of this study, those individuals were defined as male and female, with a primary medical diagnosis of schizophrenia according to Diagnostic Symptom Manual-III-Revised, and manifested negative symptoms (American Psychiatric Association, 1986). Those individuals had at least two known psychiatric admissions within the last five years, and had been previously hospitalized as inpatients, but were currently outpatients at a large private psychiatric hospital in a large urban area of California.

Observed Task Performance: The highest number of errands and/or appointments the respondent was observed to schedule in the Task: Organizing Your Day, while still adhering to the guidelines stated in the directions, as compiled by the researcher. Organizing Your Day: A simulated, functional, non-standardized, problem-solving task developed by Toglia for informal assessment of brain-injured individuals (1989a), and revised by the researcher for use with a psychiatric sample (See Appendix A). Performance: Qualitative measurement of the respondent's problem-solving ability via completion of the Task: Organizing Your Day that required the respondent ot create a schedule that allowed him or her to complete all errands and attend scheduled 
appointments. It included a pre and post questionnaire that can be quantified, and had open ended questions which can be analyzed and described in a qualitative manner by the researcher (See Appendices B and C).

Pre - Task Questionnaire: A questionnaire that asks the respondent to subjectively rate his or her problem-solving abilities in general, and specifically estimate the level of difficulty he or she would have scheduling daily activities (See Appendix B).

Pre-Task Estimation: The highest number of tasks the respondent estimated he or she could schedule in a typical day. Possible scores ranged from 0-8, based on the respondent's self-estimation on a Likert-type scale (See Appendix B).

Post - Task Questionnaire: The respondent's estimation of his or her task performance on the Task: Organizing Your Day on a Likert-type scale (See Appendix C).

Post - Task Estimation: The respondent's Post - Task estimation of his or her performance was compared to his or her observed task performance on Organizing Your Day. The respondent's estimation was recorded by the researcher as either accurate, an overestimation, or underestimation of observed task performance (See Appendix C). Self-Estimation: The patient's estimation of his or her performance before and after completing the task, as measured by the Pre - Task and Post - Task Questionnaires (See Appendices $B$ and $C$ ). The emphasis was on realistically anticipating difficulties and estimating performance, rather than improving accuracy or performance (Toglia and Golisz, 1990).

\section{Assumptions}

The researcher made several assumptions about the problem being studied. First, the assumption was made that problem-solving skills were an important element of successful performance of daily living activities for persons with schizophrenia. Second, the assumption was made that individuals diagnosed with schizophrenia may have problems estimation task difficulty. Third, the assumption was made that persons with 
schizophrenia had a tendency to overestimate their problem-solving abilities in relation to the difficulty of tasks. Fourth, the assumption was made that problem-solving and metacognitive skills were closely related.

\section{Limitations}

The implications of the results of this study are quite limited in scope. This study gathered baseline information associated with task performance of individuals with schizophrenia related to their self-estimation of problem-solving abilities. Of the $\mathbf{3 5}$ patients originally approached for participation in the study, only $\mathbf{2 0}$ met the study's criteria and agreed to participate in the data collection. Therefore, results of this study can only be applied to the individuals who were the respondents of the study. No definitive conclusions could be drawn about the relationship between perception of task abilities and actual task performance of the population of persons with the diagnosis of schizophrenia.

Other limitations were imposed by the nature of the methods used in gathering the data. Self-report methods can result in the loss of objectivity. Self-report questionnaires also contain the element of risk that the respondents would make responses based on the perceived expectations by the researcher. Imposition of biases by the researcher who assisted the respondent in completing the questionnaire was a possibility.

Respondent variability was another limitation that affected the data. The researcher had no control over the internal state of mind of the respondent, fluctuation of mood, circadian rhythms or side effects of medications being taken at the time of assessment.

Another consideration was the questionnaire designed by the researcher. The questionnaire was based on a similar study conducted with a brain-injured population. The Pre - Task and Post - Task Questionnaire, as well as the simulated functional Task: Organizing Your Day, have not been standardized. The correlation of self-estimated 
problem-solving abilities and actual task performance lacks validity and reliability testing.

The Post - Task performance estimation questionnaire did not ask the respondent to estimate the total number of tasks he or she had completed on the Task: Organizing Your Day. It only asked the respondent "Were you able to complete your errands and attend all of your appointments?". Respondents' responses to this question were agree, disagree, or neutral. Descriptive comparisons could be made between observed task performance and post - task estimation of skills, but could not be analyzed quantitatively.

Significance of the Study

Schizophrenia has a major impact on families and communities, as well as the health and social-welfare systems. Social and economic costs, estimated to be 30 billion dollars per year, identify schizophrenia as a major health care problem of the 20th century (Keith, 1988). Treatment costs exceed seven billion dollars annually, in spite of advances in efforts to manage psychotic symptoms through the use of psychopharmacologicals, a major modality in the treatment of outpatient schizophrenics. Rehabilitation failure for patients with chronic schizophrenia is common in the mental health system. Individuals with schizophrenia who are unaware of their problems are unlikely to cooperate with treatment plans or accept help from family members. Given their disabilities, these individuals may attempt to perform activities that are entirely unrealistic. Premature expectations for change or the prescription of therapeutic tasks that require adaptive efficiency, cognitive integration, and insight development are often beyond the capability of the patient (Hogarty, 1985). Recurrent exacerbations of chronic schizophrenia and persistent functional deficits in schizophrenic patients challenge clinicians to develop more effective treatment modalities (Fine, 1992).

It is evident that there is a need for more innovative and effective methods for managing schizophrenia. "In the absence of evidence that demonstrates that one cognitive rehabilitation approach is better than another, clinicians need to continue to keep 
broad perspectives, analyze the results of their treatment, and ask many questions" (Toglia, p. 139, in Katz, 1992).

Two occupational therapists, Toglia and Fine (1990), have been active in the development of an alternative cognitive approach used in the assessment and treatment of individuals with schizophrenia. The dynamic interactional model of cognition fosters a network model based on the systems theory. This theory moves beyond conventional skill-specific views of dysfunction to address underlying conditions, processing strategies, and environmental situations that influence performance. This dynamic interactional assessment approach identifies deficiencies in basic processing and self-monitoring strengths that contribute to performance (Toglia, personal communication, October 15 , 1993). Research in this area will provide clinicians with a better understanding of the numerous steps involved in problem-solving, and thus foster the development of more effective treatment planning to correct specific deficits in individuals with schizophrenia. 


\section{CHAPTER 2}

\section{LITERATURE REVIEW}

This chapter describes two approaches to cognitive rehabilitation; the deficitspecific approach and the dynamic interactional approach. Literature covering cognitive research with people with schizophrenia and with brain injury is presented. A summary of the literature reviewed concludes this chapter.

Deficit-Specific Compared With the Dynamic interactional Approach to Cognitive Rehabilitation

Occupational therapists have long treated persons within the psychosocial domain; these roots stem from the moral treatment era (Serrett, 1985). There has recently been an increased interest in developing knowledge of the relationships between cognitive deficits and functional performance. Almost all occupational models consider cognition a major performance or competence component that determines occupational performance or human occupation (Allen, 1985; Kielhofner \& Burke, 1985; Mosey, 1986; Pedretti, 1990).

\section{Deficit-Specific Approach}

How one addresses cognitive rehabilitation depends largely on how one conceptualizes cognition and cognitive functioning. Widespread acceptance of a theory of human cognition did not occur until Piaget (1954) advanced his conception of cognitive growth and development. Toglia in Katz (1992) describes cognition in the following manner:

Traditionally, cognition has been viewed as a higher-level cortical function which can be divided into separate subskills such as attention, memory, organization, reasoning and problem-solving. 
This view of cognition did not originate from theory of cognition; it was derived from psychometric models of intelligence testing and from localization approaches...Deficits were derived from performance analyses on specific tests. A poor performance on a specific test (such as a memory test) was assumed to reflect a deficiency in the specific skill (eg. memory) that the test was designed to measure. Localization approaches emphasized the correlation of specific skills and/or syndrome types to the location of the brain lesion. This approach, in combination with the traditional psychometric testing, reinforced the assumption that cognition could be divided into distinct entities. In addition, models that proposed that the brain processes first simple then complex information provided support for the view that cognitive subskills are hierarchically arranged. (p. 105)

Most current cognitive perceptual treatment programs view cognition as separate hierarchical subskills, and cognitive dysfunction is viewed as separate syndromes or deficits (Trexler, 1987).

The deficit-specific approach toward cognition included the beliefs that cognitive subskills are hierarchical in nature. Treatment involved repetitive practice of a task until the patient reached an identified criterion. Remediation was organized into activities that addressed specific deficits, derived from test performance (Trexler, 1987).

Perceptual deficits reflecting problems in the interpretation of sensory input are but one dimension of the complex interpretive failures that plague the schizophrenic patient. In some cases, cognitive remediation in clinical practice is organized around modules, such as attention or reasoning modules, and all patients receive identical treatment activities within each module. The patient progresses from one module to another until he or she 
reaches a specific level of performance criterion (Ben-Yishay and Diller, 1983). The advantages to this approach include: (a) ease of use by beginning therapists to provide identical treatment to patients with similar problems, as defined by standardized testing, and (b) deficit-specific or reductionistic approaches fit empirical research methods and produce data for outcome studies. In addition, this approach is useful in estimating what a person can and cannot do, identifying the need for treatment, and establishing performance baseline.

There are, however, disadvantages to this approach: (a) this reductionism approach does not describe how specific skills interrelate during cognitive processing and task performance. For example, labels such as "problem-solving" do not specify which characteristics of reasoning contribute to either high or low performance (Toglia in Katz, 1992), and (b) this approach does not provide information about a person's potential for change, an issue of growing importance to rehabilitation specialists, administrators and third-party payers. Concerns might include: How orderly and extensive are the patient's problem-solving strategies? To what extent does the patient proceed with decisions in response to environmental demands?

Identifying conditions that facilitate performance are of particular importance for individuals with schizophrenia (Fine, 1992). Cognitive problems often overiap and correlate with one another, which leads to the question of the usefulness of this division (Toglia \& Golisz, 1990). There is compelling evidence that deficit-specific approaches to cognitive rehabilitation are not adequately precise. Syndromes, such as visual agnosia, group patients together who present highly heterogeneous deficits (Seron \& Deloche, 1989).

Allen's Cognitive Levels

Allen's Cognitive Levels (ACL), is a cognitive assessment model developed by Claudia Allen. It is widely used by occupational therapists and uses neither a deficit- 
specific nor dynamic interactional approach to cognitive functioning. Instead, Allen uses an adaptive approach emphasizing the importance of adapting the environment to the individual, rather than adapting the individual to the environment. The focus of her approach is training the caregiver, accordingly, based on the patient's current level of function (J. P. Toglia, personal communication, June 19, 1995). Allen's assessment tool was originally developed to classify cognitive levels of psychiatric patients. Allen (1985) has identified hierarchical levels of cognitive function. These cognitive levels are classified on a scale of 1-6, and describe behaviors ranging from severely impaired to normal. The emphasis is on current functional abilities and social abilities instead of cognitive dysfunction. The purpose of the assessment is to provide a guideline for determining the amount and type of caregiver assistance needed, and for predicting the patient's ability to do new and familiar activities rather than to identify and monitor specific strengths and weaknesses underlying performance (Allen, 1987; Allen, 1988). The scale only provides a general description of the range of abilities and limitations. A more detailed assessment is needed to identify underlying processes that contribute to problem-solving deficits.

\section{Dynamic Interactional Approach}

A contrasting approach to deficit-specific cognitive rehabilitation is the dynamic interactional approach. The dynamic interactional approach is not meant to replace conventional, deficit-specific assessments that identify strengths and weaknesses. This approach is intended to supplement traditional testing procedures and provide additional information regarding the underlying processing skills that contribute to task performance. The dynamic approach to cognitive rehabilitation defines cognition in terms of global capacities. Characteristics of a dynamic approach include the following: (a) treatment is delivered in a reactive mode; the person's response determines what kind of therapy is administered, (b) there is little emphasis placed on the absolute level of performance on specific tests, and (c) there is no predetermined or prescribed sequence of treatment 


\section{PLEASE NOTE}

Page(s) not included with original material and unavailable from author or university. Filmed as received.

\section{UMI}


concerning their cognitive abilities.

The dynamic interactional approach is grounded in systems theory and uses an information processing model and task analysis. Essential to the conceptualization of cognition is the notion that cognition is an ongoing product of the dynamic interaction between the person, the task and the environment. One must first analyze the interaction between all three components in order to understand cognitive function (Toglia, 1989a). Cognition is viewed as a dynamic interaction between the person or role, (cognitive capacity, strategies, metacognition, and learner characteristics, such as motivation), the task, and the environment (social, physical, and cultural) (Toglia in Katz, 1992). This model stems from systems theory, and is organized under a person-environmentperformance conceptual framework in occupational therapy (Christiansen in Christiansen \& Baum, 1992). Many discrete factors interact during information processing. A brief definition of the three components that comprise the dynamic interactional model follows the section on systems theory.

\section{Systems Theory}

Toglia's (1992) dynamic approach toward assessment and treatment of cognitive dysfunction draws on the principles of systems theory and uses a input, processing, output, feedback model (Toglia in Katz, 1992). It has been hypothesized, based on the model, that individuals with schizophrenia are markedly deficient in their problem-solving abilities (Bellack, Morrison, \& Mueser, 1989). Poor problem-solving ability is an example of a deficiency in processing strategies. Processing strategies (also referred to as the feedback loop) are the observable behaviors that are reflective of the input and processing of information, or the information from environmental transactions. Information processing is divided into three stages: input, processing, and output. The input stage involves getting the information from self and the external environment. The processing stage involves linking perceptions and appraisal of input information based on previous 
experience and expectations, and formulating decisions. The output stage involves a behavior transaction: a verbal, written, gestural, or motor response with the environment (Toglia in Katz, 1992; Christiansen in Christiansen \& Baum, 1992; Levine \& Brayley in Christiansen \& Baum, 1992). Metacognitive skills can influence all stages of information processing (Toglia in Katz, 1992).

Specifically, the dynamic interactional approach of cognitive rehabilitation in occupational therapy, though in its initial stages of development, attempts to address the underlying processing skills (metacognitive skills) involved in problem-solving (Toglia, 1989a). The literature added support to this approach by suggesting that those treatment techniques that aim to help the patient detect errors, predict outcomes, estimate task difficulty, and evaluate performance outcome are believed to increase in sight and selfmonitor skills related to problem-solving (Ben-Yishay \& Diller, 1983; Cicerone \& Wood, 1987; Lawson \& Rice, 1989; McGlynn \& Schacter, 1989; Pollens, McBratnie \& Burton, 1988). Schizophrenic individual exhibiting negative symptoms have well-documented cognitive impairment and structural brain abnormalities (Crow, 1985). The finding in this group provided justification for utilizing Toglia's (1989a) dynamic assessment approach which was then used more extensively with brain-injured patients (Toglia in Katz, 1992). Structural Capacity. Processing Strategies and Behaviors

Structural capacity refers to the physical limitations of information processed by a human being at a given time. Processing strategies and behaviors are organized approaches or tactics that operate to select and guide the processing information (Abreu \& Toglia, 1987; Lidz, 1987). These processing strategies can be introduced to the individual to make more efficient use of the information processing system. An example of this is a person who, when confronted with a large amount of information, begins to select automatically the most relevant stimuli and ignore the irrelevant stimuli (Abreu \& Toglia, 1987). This strategy is deficient in many individuals with schizophrenia. Processing 
strategies are the most observable aspects of a learner's performance. These strategies or behaviors can be effective in specific tasks or environments and applicable in a wide range of tasks and environments (Toglia, 1989a).

In addition, these strategies are overseen and managed by metacognitive processes. Metacognition refers to knowledge and regulation of one's own cognitive processes and capacities (Flavell, 1985). Metacognitive processes are the ability to plan ahead, evaluate task difficulty in relation to current skills, choose appropriate strategies, and monitor performance (Toglia, 1991). These skills are prerequisites to the selection and application of strategies. They have been shown to be critical components involved in leaming and generalization of new information (Belmont, Butterfield \& Ferretti, 1982). Individual characteristics such as knowledge, motivation, and emotions will influence the degree to which information is processed and monitored (Brown, 1988). Information processing involved in problem-solving can be motivated by external stimuli, or it can be driven by internal expectations and prior experiences. An individual's motivation and emotional state will influence the extent to which information is processed deeply and is monitored (Bandura, 1988). The more perceived control an individuals believes he or she has over a situation, the better he or she will perform. One's ability to predict results and estimate task difficulty is related to motivation. If a person consistently overestimates his or her abilities and inaccurately anticipates the consequences of those actions due to inferior insight, it may be perceived that her or she has no control over his or her performance and subsequently feels an external locus of control exists (Kielhofner \& Burke, 1985; Toglia in Katz, 1992).

\section{Environmental Component}

The environmental component is made up of social, physical, and cultural elements and can influence one's ability to process information and adapt to demands. The social environment includes the persons with whom the individual interacts, and it has been 
argued that much of learning and higher cognitive skills are mediated through social interaction (Feuerstein, 1979; Vygotsky, 1978). Social interactions can transform or mediate incoming information either to enhance or impede information processing (Jensen \& Feuerstien, 1987). The physical environment consists of the actual materials and objects that surround a person. Cultural environment includes the values and expectations of one's cultural group. Familiar physical and cultural environments have the ability to influence one's ability to process information because he or she can provide contextual cues which call upon previous knowledge and skills, and aid in processing of new information (Abreu \& Toglia, 1987).

\section{The Task Component}

The task component is the final element in the dynamic interactional model. The task is comprised of two levels: surface characteristics and conceptual characteristics. Surface characteristics are the observable elements of a task, such as the number of items, directions needed for the task, the type of stimuli, or the variable attributes. Conceptual characteristics are the underlying processing skills and strategies needed to perform the task which are not directly observable (Toglia, 1991). These task characteristics may determine the self-monitoring skills and processing strategies needed to perform the task. For example, a person may be able to sort 15 cards into meaningful categories, but is unsuccessful when the number of cards is increased to 40 . By analyzing the conceptual task characteristics, a clinician begins to understand the conditions that contribute to the breakdown of information processing that affects performance. This differs from the deficit-specific approach in which the deficit is defined by the task.

This model views cognition as the dynamic interaction between the person, the environment, and the task; to understand cognitive function all three components must be analyzed (Toglia in Katz, 1992). The environmental component may affect cognitive 
processing between the person and the task component. Task characteristics may influence the environment or information processing of the person. Finally, a person's individual characteristics may be the primary factor influencing cognition.

Cognitive Research on Individuals With Schizophrenia

The dynamic interactional model of cognition assumes that a number of metacognitive skills may influence performance on any cognitive task. This study chose to provide an in-depth investigation of one aspect of this model, metacognitive skills, with one type of cognitive task. The following is a review of recent literature on the subject of awareness and schizophrenia.

Lack of insight is the most prevalent symptom in schizophrenia disorders, and it occurs more frequently in schizophrenia that in other psychotic disorders such as depression (Amador, Strauss, Yale, \& Gorman, 1991; Carpenter, Strauss \& Bartko, 1973). Cognitive impairments play a central role in the problems that individuals with schizophrenia experience in daily living. Cognitive demands in social encounters include decision-making, judgment, and problem-solving. Pronounced deficits of individuals with schizophrenia are particularly evident on perceptual and cognitive tasks that involve complex information processing (Goldstein, 1986).

Lack of insight has been conceptualized from several theoretical perspectives. Psychoanalytic notions of denial of illness, or abnormal psychological defense mechanisms, or abnormal coping mechanisms have been hypothesized. A neuropsychological etiology has been suggested for lack of insight in individuals with schizophrenia, mainly based on frontal, right parietal, right hemisphere, or diffuse cerebral dysfunctions (Cuesta \& Peralta, 1994). An alternative hypothesis, the clinical hypothesis, proposes that lack of insight arises directly from the illness process and could be considered as a "primary" symptom (Bleuler, 1983).

Individuals with schizophrenia have often been observed to ignore the deficits 
caused by their iliness and the effect their illness has on their lives. Clinicians treating individuals with schizophrenia frequently encounter the individual's denial of illness and symptoms; this is often a barrier between patient and professional. Patients have reported feeling coerced into accepting treatment for an illness they do not think they have. Studies indicate that better insight into illness and symptoms, and better insight regarding benefits of treatment bode well for positive clinical outcome and compliance with treatment (Amador \& Strauss, 1993). Poor insight was associated with decreased Global Assessment of Functioning scores (GAF). However, the literature reported that many patients with schizophrenia who are aware of particular symptoms remain completely unaware of other symptoms (McGlynn \& Schacter, 1989).

Cognitive Research on Brain Injured Individuals

Several studies have been performed on awareness of disease following head trauma. Researchers Anderson and Tranel (1989) performed a study of 100 patients with cerebral infarction, dementia, or head trauma, using a standardized interview which elicited subjects' descriptions of their condition. "Unawareness" was operationally defined as a discrepancy between the subject's description of abilities, and measurement of those abilities with neurological evaluation. The findings of this study showed that subjects in all groups frequently demonstrated unawareness of acquired impairments. Sixty-eight percent of the head trauma subjects underestimated their deficits in the area of cognitive function, including intellect, orientation, memory, language, and visuoperception. The areas of cognitive function in which unawareness of deficits was most frequently present across all groups were intellect and memory (Anderson \& Tranel, 1989). The results of their study supported the findings of other researchers in this area that "one of the most prevalent problems encountered by rehabilitation professionals in patients with head injuries is the patients' lack of awareness of even their most blatant deficits" (Anderson \& Tranel, 1989, p. 336). Prigatano (1991) wrote that brain-injured individuals do not 
adequately perceive significant changes in their higher cerebral functioning. Therefore, they may choose a level of work that is not appropriate for their abilities. Traumatic brain injured individuals were often found to underestimate the severity of their behavioral problems when compared to the estimations of their families' reports.

Schizophrenic individuals exhibiting negative symptoms have well-documented cognitive impairment and structural brain abnormalities (Crow, 1985). The findings on this group provides justification for utilizing Toglia's (1989a) dynamic assessment approach which has been used more extensively with brain-injured patients

\section{Summary}

Occupational therapists treat patients with schizophrenia in all stages of their illness, and in all settings from the hospital to the community (Katz in Katz, 1991). Of the approximately two million Americans who struggle with symptoms of schizophrenia, successful occupational performance is often an elusive and overwhelming phenomenon. The most fundamental tasks of daily living may represent enormous challenges. Individuals with schizophrenia have been shown to exhibit poor problem-solving abilities. Problem-solving is a critical task of daily living, and deficits in this skill can compromise the occupational roles of the individual. Rehabilitation failure among patients with persistent deficit symptoms, such as schizophrenia, is evident in the mental health system. Many highly lauded social skills training programs often fail to consider adequately the underlying cognitive deficits that influence social capacities and predict readiness and accessibility for a given treatment strategy (Fine, 1992).

The dynamic interactional approach to cognition attempts to address the underlying processing skills, environment, and tasks that contribute to task performance. The assessment of cognitive abilities includes estimates of the potential for learning and looks at how a person goes about solving problems and dealing with situations. This approach looks at a person's processing strategies during task performance, and 
assesses whether the person has the underlying capabilities to initiate efficient processing strategies.

The development of cognitive theoretical approaches in occupational therapy integrates knowledge of cognition from different scientific disciplines within occupational therapy theories and principles. The dynamic interactional approach offers a new perspective to the conceptualization of cognition. This approach attempts to expand the vision of cognition by determining the conditions under which a person is likely to succeed, as well as those under which he or she is likely to fail.

Individuals with schizophrenia exhibit symptoms of cognitive impairment. Research with people with brain injury who have cognitive impairment suggests that the dynamic interactional approach could be useful in assessing the cognitive abilities of people with schizophrenia. 


\section{CHAPTER 3}

\section{DESIGN AND METHODOLOGY \\ Design}

This study used a simple pre - test, post - test design with survey questionnaire to gather the data for this research. A Pre - Task questionnaire was administered prior to the completion of a simulated functional Task: Organizing Your Day was performed. A Post - Task questionnaire was then administered.

\section{Objective}

The objective of this study was to describe the relationship between the selfreported perceptions of a sample of individuals with schizophrenia, regarding their ability to evaluate task difficulty, and their subsequent performance on a cognitive task.

\section{Questions}

The research questions generated for the study were:

1) To what degree are individuals with schizophrenia able to estimate their performance Pre - Task?

2) If Pre -Task estimations differ from task performance, do individuals with schizophrenia overestimate or underestimate their abilities?

3) To what degree are individuals with schizophrenia able to overestimate or underestimate their performance Post - Task?

\section{Respondents}

Respondents involved in the study were 20 male and female patients with the diagnosis of schizophrenia, and evidence of chronicity which was determined by multiple numbers of hospitalizations. The Diagnostic Symptom Manual-III-Revised (American Psychiatric Association, 1987) describes the diagnosis of schizophrenia as based on positive and negative symptoms, age, the number of previous psychiatric admissions. 
This description was used in the selection process of respondents for this study. Respondents for this study manifested negative symptoms. Persons exhibiting positive symptoms, characterized by prominent delusions, hallucinations, and persistently bizarre behavior were excluded from the study. The Pre - Task Questionnaire asked the respondents if they had any eyesight problems that would prevent them from reading the questionnaire. There were three possible answers to this question: yes, no, and unsure. Those respondents who reported experiencing eyesight problems were excluded from the study. All respondents were at least 18 years of age.

The researcher selected respondents via chart review at a Partial Hospitalization Program in California. Respondents who met the criteria of a diagnosis of schizophrenia with negative symptoms were selected consecutively over a three- month period between February and April, 1994. Twenty of 36 individuals met the baseline criteria, consented to participate in the study (See Appendix D), and completed all phases of data collection. The study group consisted of 20 male and female individuals between the ages of 24 and 68 who carried a diagnosis of schizophrenia and who were participating in the Partial Hospitalization Program. Consent for participation was received from the facility (See Appendix E).

Instruments

\section{Pre - Task Questionnaire}

The Pre - Task Questionnaire (See Appendix B), was developed by the researcher, at the suggestion of Reader Toglia (personal communication, October 15, 1993) The purpose was to assess the respondent's Pre - Task estimation of his or her schedule-making abilities for activities of daily living. The Pre - Task Questionnaire required the respondent to report if he or she had any eyesight problems that would prevent him or her from reading the questionnaire. There were three possible answers to this question. The choices were yes, no, and unsure. Those respondents who reported 
experiencing eyesight problems were excluded from the study.

Respondents were then asked to estimate their ability to organize daily activities, as well as their ability to solve a problem based on past experiences. Each question had five possible answers: strongly disagree, somewhat disagree, neutral, somewhat agree, strongly agree. The respondents were then asked to estimate the difficulty they would experience in making a daily schedule if they had to schedule from one to eight tasks to perform.

The Pre - Task Questionnaire asked the respondents to complete the following open-ended question: "if you have problems getting everything done each day, what kind of problems do you usually have?" An open-ended question was chosen to elicit the respondents' reasons, if any, for not being able to perform multiple tasks that are required in making a daily schedule. Respondents wrote their answers in space provided on the Pre - Task Questionnaire.

\section{Organizing Your Day}

The simulated functional assessment Task: Organizing Your Day (See Appendix A) is a paper-and-pencil test used to measure the respondent's ability to solve a problem that he or she may encounter in everyday life. The Task: Organizing Your Day required approximately 20 minutes to administer. This protocol has been used clinically to evaluate respondents with traumatic brain injuries. It has not been standardized and does not meet traditional reliability or validity standards (Toglia, 1992). This approach is not intended to replace tests that identify cognitive deficits and quantify strengths and weaknesses. Rather, it was designed to provide additional information that will have a direct impact on intervention by providing guidelines for future treatment strategies (Toglia 1989).

Briefly, the task component is the final element in the dynamic interactional model discussed in the literature review in Chapter Two. The task is comprised of two levels, 
surface characteristics and conceptual characteristics. Surface characteristics are the observable elements of a task, such as the number of items, directions needed for the task, the type of stimuli, or the variable attributes. Conceptual characteristics are the underlying processing skills and strategies needed to perform the task which are not directly observable (Toglia, 1991). These task characteristics may determine the selfmonitoring skills and processing strategies needed to perform the task. By analyzing the conceptual task characteristics, a clinician begins to understand the conditions that contribute to the breakdown of information processing that affects performance. This differs from the deficit-specific approach where the deficit is defined by the task.

The Task: Organizing Your Day was modified by the researcher with Toglia's verbal permission (See Appendix F). Modification included changes in both layout and content. The researcher shortened the number of errands included in the original task, drew a map of the location of businesses and offices, provided the respondent with a worksheet to schedule his or her errands, and geared the errands toward a psychiatric population. For example one of the original errands on the Task: Organizing Your Day was to "fill the car up with gas:" Since most respondents included in this study did not drive, the researcher believed this to be an unrealistic errand for this population and omitted it from the Task: Organizing Your Day which required the respondent to read a short paragraph and construct a daily schedule that involved the use of problem solving skills. Information was given to the respondent concerning the opening and closing times for businesses and the times of scheduled appointments. The respondent was required to construct a schedule for the day that would enable him or her to successfully complete errands and attend scheduled appointments. Based on Toglia's suggestions and scoring of the Task: Organizing Your Day, the successful respondent was required to schedule five key errands in a particular order, as well as schedule the additional three tasks to achieve a perfect score of eight. It was necessary for the respondent to schedule the five 
key errands as follows: (a) go to the bank first, before purchasing anything, because all purchases were to be made in cash; (b) Schedule the doctor's appointment for 2:00 p.m.; (c) Pick up the ice cream cake as the last errand of the day or it would melt; (d) Schedule Bill's party for 8:00 p.m.; and (e) Meet Mary for lunch at anytime between the reasonable restaurant lunch hours of 10:00 a.m. to 4:00 p.m. The additional three errands could be scheduled throughout the day as long as they were not scheduled after the stores and businesses had closed for the day. Task performance was scored according to the highest number of errands or appointments the respondent was observed to successfully schedule into his day, and still meet the expectations described in the task directions (See Appendix A).

\section{Post - Task Questionnaire}

Following the Task: Organizing Your Day, a Post - Task Questionnaire was administered that required the respondents to estimate Post - Task performance. This questionnaire was developed by the researcher at the suggestion of Toglia (personal communication, October 15,1993$)$. The purpose of the questionnaire was to assess if the respondents were able to monitor their performance after completing the task. Metacognitive skills include the ability to self-monitor performance. These skills have been identified by several authors as critical components in the learning and generalization processes (Belmont, Butterfield, \& Ferretti, 1982). One of the questions asked "do you agree or disagree that you were able to complete all of your errands and scheduled appointments?" (See Appendix D). There were five possible answers: (1) strongly disagree, (2) disagree, (3) neutral, (4) somewhat agree, and (5) strongly agree. An openended question "if you could not complete your errands and attend your appointments, what happened?" was asked on the Post - Task Questionnaire. An open-ended question was chosen to elicit respondents' reasons for not being able to complete the tasks on Organizing Your Day. Respondents wrote their answers in space provided on 
the Post - Task Questionnaire.

\section{Procedures}

The researcher met individually with each of the respondents and gave verbal directions for completion of the questionnaire. The respondent was asked to sign a release form for participation in the study. The researcher passed out the questionnaires and task and asked the respondents to carefully read the task directions before starting the task. The researcher clarified the task directions if asked, but did not assist the respondent in completing the task. The researcher encouraged each respondent to do his or her best on the task. The researcher remained with each respondent during the administration of the Pre - Task Questionnaire, the Task: Organizing Your Day, and the Post - Task Questionnaire. The respondent was first asked to complete the Pre - Task Questionnaire, immediately afterward the respondent was asked to construct a daily schedule from Organizing Your Day that allowed him or her to complete errands and attend scheduled appointments. The respondent wrote his or her schedule on a separate worksheet that was organized into hourly increments for convenience (See Appendix G). Respondents who disregarded the task instructions and included their own ADL were asked to re-read the directions. The researcher again clarified the Task directions but did not provide the respondent with any additional assistance to complete the task. Following the Task: Organizing Your Day, the respondent was asked to complete the Post - Task Questionnaire. During the administration of the Pre - Task Questionnaire, the Task: Organizing Your Day and Post - Task Questionnaire, the researcher sat near the respondent but did not offer any additional assistance, cueing or encouragement. After completing the questionnaires and task, all paper work was collected and stored in a locked file cabinet. The respondent was thanked for his or her participation.

Privately, the researcher numerically scored the respondents' Pre - Task Questionnaire and placed the score directly on the Pre-Task Questionnaire according to 
the highest number of tasks the individuals estimated he or she would be able to complete. Next, scheduled tasks from Organizing Your Day were tallied by the researcher and numericaily recorded on the same worksheet the respondent scheduled his or her tasks. The researcher scored Organizing Your Day task performance according to the highest number of errands or appointments the respondent scheduled successfully into his day, and met the described expectations in the task directions (See Appendix A). Post - Task Questionnaire estimations were tallied on the Post - Task Questionnaire. 'Results of the respondents' Pre - Task and Post - Task estimation scores were later compared to the number of tasks each respondent was able to successfully schedule on Organizing Your Day.

The data gathered were compared with the respondents' perceived problemsolving capacities prior to and after performing the task. The entire assessment required no longer than 30 minutes. The names of the respondents were not used. The questionnaires were identified by using a code to ensure their privacy.

\section{Content Validity}

To establish content validity, Organizing Your Day was administered to a volunteer, convenience sample of ten San Jose State University graduate occupational therapy students to establish whether task performance could be completed with $100 \%$ accuracy, in a "normal" group. $100 \%$ of the graduate occupational therapy students successfully scheduled the eight tasks contained in Organizing Your Day.

Data Analysis

Pre - Task Data Analysis

The Pre - Task Questionnaire asked the respondent the following question "will you have any difficulty making a schedule for yourself if you had one thing to do?" Those respondents who answered somewhat agree or strongly agree to the preceding question were scored as yes. This was an estimation that the respondent would have 
difficulty completing the task. Those questions self-reported as strongly disagree or somewhat disagree to the question, "will you have any difficulty making a schedule for yourself if you had one thing to do?" were scored as no. This was an estimation that the respondent would not have difficulty completing the task. An answer of neutral to the question "will you have any difficulty making a schedule for yourself if you had one thing to do?" was considered unsure, and also scored as yes. This was an estimation that the respondent would have difficulty completing the task. A numerical value of estimated daily activities that could be scheduled was determined by the highest number of somewhat disagree or strongly disagree responses, and was recorded directly on the Pre - Task Questionnaire (See Appendix B). Data recorded on the Pre - Task Questionnaire were transferred to a computer spreadsheet. The highest number of estimated tasks the respondent perceived he or she could complete on the Pre - Task Questionnaire was compared with the highest number of tasks the respondent scheduled correctly on the Task: Organizing Your Day. Discrepancies in scores were noted on a data sheet as either an overestimation or underestimation of performance Pre - Task.

\section{Task: Organizing Your Day Data Analysis}

Study data were collected via a self-report questionnaire from individuals with schizophrenia. On the Task: Organizing Your Day, scheduled tasks were tallied by the researcher according to the highest number of errands or appointments the respondent scheduled successfully into his or her day while meeting the expectations described in the task directions (See Appendix A). Possible scores ranged from zero to eight tasks. For convenience, a pre-printed schedule form was provided to the respondent to write his or her schedule (See Appendix G). The highest number of successfully scheduled tasks tallied by the researcher were recorded on the same form the respondent scheduled his or her tasks (See Appendix G). 


\section{Post - Task Data and Analysis}

Following the Task: Organizing Your Day, data were collected to assess a respondent's estimation of task performance. The questionnaire asked the question "do you agree or disagree you were able to complete all of your errands and scheduled appointments?" (See Appendix C). There were five possible answers: (1) strongly disagree, (2) somewhat disagree, (3) neutral, (4) somewhat agree, and (5) strongly agree. Responses to this question were scored as $\underline{1}, \underline{2}, \underline{3}, \underline{4}$, or $\underline{5}$, directly on the Post - Task Questionnaire. The researcher compared the number of tasks scheduled correctly on the Task: Organizing Your Day, with the respondent's assessment of his or her task performance on the Post - Task Questionnaire. Discrepancies between scores on the Task: Organizing Your Day and Post - Task Questionnaire estimations of performance were noted as either an overestimation or underestimation of performance Post - Task.

To determine if a respondent underestimated, overestimate or accurately estimated Post - Task performance, the researcher used the following method. For all those who responded (4) somewhat agree or (5) strongly agree on completion of all tasks, the researcher looked at the observed number of tasks that the respondent scheduled for him or herself. If the respondent was observed to complete fewer than eight items in the task, then he or she was perceived to be overestimating his or her performance Post - Task.

For all those who responded (1) strongly disagree or (2) somewhat disagree on completion of all tasks, the researcher looked at the number of tasks the respondent scheduled for him or herself. If the respondent did not complete all eight tasks, then he or she was perceived to be accurately estimating his or her Post - Task performance. If the respondent did in fact compete the task with a perfect score of eight items, then he or she 
was perceived as underestimating his or her performance Post - Task.

For all those who responded (3) neutral on completion of all tasks, the researcher scored as neutral. The researcher did not look at the number of tasks the respondent scheduled for him or herself. No comparison of over or under estimation of task performance was made. These individuals were apparently unable to agree or disagree if they had completely scheduled all of their errands and were able to attend all appointments.

Reasons for not being able to complete the schedule on the Task: Organizing Your Day were gathered through an open-ended question on the Post - Task Questionnaire. The researcher did not use pre-determined categories. Written responses to this question were collected on index cards and organized first into preliminary categories emerging from recurrent responses given by the various respondents. Various broad categories emerged from data collected. The preliminary categories were organized into larger categories, based on similarities. From these larger categories, patterns or themes emerged. These themes were analyzed and interpreted in a narrative fashion.

\section{Statistical Analysis}

\section{Pre - Task Questionnaire Data Compared to Organizing Your Day Data}

Estimate scores gathered from results of the Pre - Task Questionnaire were tabulated and recorded on the computerized spreadsheet program Microsoft Excel. The mean and median score, and the standard deviation from the mean score were generated from Pre - Task Questionnaire data using the computer program Statworks (Datamatrics, Inc.). Task scores gathered from results of the Task: Organizing Your Day were tabulated and recorded on the computerized spreadsheet program Microsoft Excel. The mean and median score, and the standard deviation from the mean score were generated from Organizing Your Day data using the computer program Statworks (Datamatrics, Inc.). The mean values of the predicted scores gathered from the Pre - Task Questionnaire and 
observed scores collected from Organizing Your Day were compared using a paired, twotailed Student's T-test. A Student's T-test was used to determine the statistical difference (if any) between mean scores on Pre - Task estimations and Task scores on Organizing Your Day.

\section{Content Analysis of Qualitative Responses to Open-Ended Questions}

Two qualitative, open-ended questions were inciuded in the study. The first question was "if you have problems getting everything done each day, what kind of problems do you usually have?" Written responses to this question were recorded on index cards and organized first into clusters or piles of index cards. There were no prearranged categories or clusters chosen by the researcher. Preliminary categories emerged from recurrent responses given by the various respondents. Themes emerged from these categories. For example, from the clusters of responses, the researcher noted that several respondents had written that "lack of will"; "incentive"; "motivation"; and simply "getting out of bed" interfered with their ability to get things done during the day. Thus, lack of motivation emerged as a theme contributing to inability to perform daily tasks.

The various themes that emerged were compared and condensed. For example, two different themes developed from categories, transportation and lack of money and were condensed into one larger category of external influences. These two themes . shared the common concept that transportation and lack of money were outside tangibles that contributed to the respondent's inability to complete daily tasks. Further interpretations of these themes and patterns are reported in the discussion section of this study.

The second question asked, "if you could not complete your errands and attend your appointments, what happened?" Written responses to this question were also gathered and organized first into clusters or piles of index cards. There were no pre- 
arranged clusters or categories chosen by the researcher. Preliminary categories emerged from written recurrent responses given by the various respondents for the question. For example, the researcher noted that several respondents had written that feelings such as "I'm feeling ill"; " (l'm) having low blood sugar and I'm tired"; and "my head hurts, I'm dizzy" interfered with their ability to complete the schedule-making task. These responses were clustered together and the theme physical complaints emerged as a theme contributing to inability to perform successfully on the Task: Organizing Your Day.

Themes were condensed into patterns in the same fashion as those in the Pre - Task Estimation qualitative question discussed in the former section. Further interpretations of these patterns were reported in the discussion section of this study. 


\section{CHAPTER 4}

\section{DATA AND RESULTS}

\section{Organization of Chapter}

This chapter on data and results is organized in the following manner:

1) Demographics are reported; 2) Pre - Task estimations, the Task: Organizing Your Day scores, and Post - Task estimations are reported; 3) Pre - Task estimations are compared to demonstrated ability to schedule tasks; 4) Post - Task estimations are compared to demonstrated ability to schedule tasks; 5 ) Responses to open-ended questions on the Pre - Task and Post - Task Questionnaire are given; 6) The research questions are answered.

\section{Demographics}

The research sample which were identified via chart review was comprised of 16 males ( $80 \%)$ and four females (20\%). The ages ranged from 24 to 67 with the average age of 37.3. The predominant schizophrenic subgroup diagnosis was paranoid schizophrenia (90\%). Other demographics were: Ninety-five percent of the research respondents were single, $5 \%$ were married, $60 \%$ lived in board and care homes, $30 \%$ lived independently, and $10 \%$ lived with family members. Ninety percent of the sample had a Graduate Equivalency Diploma (GED) equivalent and $25 \%$ of those graduating from high school attended college. For $45 \%$ of the respondents, onset of schizophrenic symptoms occurred in the teen years, the remaining 55\% respondents experienced onset in their twenties. All of the persons involved in the study were receiving Social Security Insurance (SSI), but $60 \%$ had a previous work history. 
Pre - Task Estimations, Task: Organizing Your Day Scores, and Post - Task Estimations

Pre - Task Estimations

Subjects' estimated scores on the Pre - Task Questionnaire ranged from zero to eight on a scale of possible scores from zero to eight. Of the 20 respondents, five (25\%) achieved Pre - Task estimations of zero. One (5\%) respondent scored a Pre - Task estimation of one. Two (10\%) estimated a Pre - Task score of two. Five (25\%) scored Pre - Task estimations of three. Three (15\%) estimated a Pre - Task score of four. Three (15\%) scored Pre - Task estimations of five. One (5\%) respondent estimated a Pre Task score of eight. No respondents achieved estimated scores of six or seven (See Table 1).

\section{Task: Organizing Your Day Observations}

Scores among the individuals in the schizophrenic group ranged from zero to eight on a scale of a maximum score equal to eight. Three or $15 \%$ demonstrated ability to schedule tasks that earned a score of zero. Two or $10 \%$ demonstrated ability to schedule tasks that earned a score of one. One or $5 \%$ demonstrated ability to schedule tasks that earned a score of two. Five or $25 \%$ demonstrated ability to schedule tasks that earned a score of five. Three or $15 \%$ demonstrated ability to schedule tasks that earned a score of six. Four or $20 \%$ demonstrated ability to schedule tasks that earned a score of seven. Two or $10 \%$ demonstrated ability to schedule tasks that earned a score of eight. No respondents achieved scores of three or four (See Table 2).

\section{Post - Task Estimations}

On the Post - Task Questionnaire, subjects estimated their performance on the Task: Organizing Your Day by rating their performance on a scale from strongly disagree (1) to strongly agree (5). Eight or $40 \%$ of the respondents scored strongly agree (5) which indicated that they estimated that they were able to complete scheduled 
Table 1

Pre - Task Estimations $(\underline{N}=20)$

\begin{tabular}{lll}
\hline Pre - Task Estimations & $\underline{n}$ & Percent \\
\hline 8 & 1 & .05 \\
7 & 0 & .00 \\
6 & 0 & .00 \\
5 & 3 & .15 \\
4 & 3 & .15 \\
3 & 5 & .25 \\
2 & 2 & .10 \\
1 & 1 & .05 \\
0 & 5 & .25 \\
\hline
\end{tabular}


Table 2

Demonstrated Performance Scores on the Task: Organizing Your Day $(\mathbb{N}=20)$

\begin{tabular}{lll} 
Task Scores & n & Percent \\
\hline 8 & 2 & .10 \\
7 & 4 & .20 \\
6 & 3 & .15 \\
5 & 5 & .25 \\
4 & 0 & .00 \\
3 & 0 & .00 \\
2 & 1 & .05 \\
1 & 2 & .10 \\
0 & 3 & .15 \\
\hline
\end{tabular}


appointments and errands successfully. Four or $20 \%$ of the respondents scored somewhat agree (4) which indicated their estimation of their ability to successfully complete the schedule of errands and appointments. Five or $25 \%$ of the respondents scored neutral (3). Two or $10 \%$ scored somewhat disagree (2). One or $5 \%$ of the respondents scored strongly disagree (1) (See Table 3).

Pre - Task Questionnaire Estimations Compared to Demonstrated Performance

\section{on the Task: Organizing Your Day}

Of the 20 respondents, three or $15 \%$ overestimated their ability in comparison to demonstrated performance on the Task: Organizing Your Day. Three respondents or $15 \%$, accurately predicted their ability. The remaining $70 \%$ or 14 respondents underestimated their ability in relation to demonstrated task performance on the Task: Organizing Your Day (See Table 4).

Of the 14 respondents who underestimated on Pre - Task scores when compared with demonstrated performance on the Task: Organizing Your Day, three respondents estimated ability to perform three tasks and demonstrated ability to score five; two estimated ability of zero and demonstrated ability to score two and seven respectively; one estimated Pre - Task ability of one and demonstrated ability to score seven; two estimated a score of two and achieved scores of five and six respectively; three estimated scores of four scored five, six, and eight respectively; three estimated a score of five and achieved scores of six, seven, and eight tasks.

Three respondents or $15 \%$, overestimated Pre - Task scores in relation to demonstrated task performance on the Task: Organizing Your Day. Two individuals estimated Pre - Task scores of three and each scheduled one task on Organizing Your Day, one respondent estimated a Pre - Task score of eight and scheduled seven tasks. Three respondents, or $15 \%$ accurately estimated Pre - Task estimations of zero, and demonstrated ability with a score of zero. 
Table 3

Post - Task Estimations $(\mathbb{N}=20$ )

\section{Post-Task Estimations $\underline{\text { n }}$ Percent}

$\begin{array}{lll}5 & 8 & .40 \\ 4 & 4 & .20 \\ 3 & 4 & .25 \\ 2 & 5 & .10 \\ 1 & 2 & .05\end{array}$


Table 4

Comparison of Pre - Task Estimation Scores and Demonstrated Performance Scores on the Task: Organizing Your Day $(\underline{N}=20)$

\begin{tabular}{|c|c|c|c|}
\hline Respondents: & Predicted score & Task score & Over/Und/Acc \\
\hline 1 & 3 & 5 & Under \\
\hline 2 & 3 & 1 & Over \\
\hline 3 & 2 & 6 & Under \\
\hline 4 & 5 & 6 & Under \\
\hline 5 & 0 & 0 & Accurate \\
\hline 6 & 5 & 8 & Under \\
\hline 7 & 4 & 8 & Under \\
\hline 8 & 4 & 6 & Under \\
\hline 9 & 4 & 5 & Under \\
\hline 10 & 3 & 5 & Under \\
\hline 11 & 8 & 7 & Over \\
\hline 12 & 0 & 2 & Under \\
\hline 13 & 2 & 5 & Under \\
\hline 14 & 0 & 0 & Accurate \\
\hline 15 & 0 & 0 & Accurate \\
\hline 16 & 0 & 7 & Under \\
\hline 17 & 3 & 5 & Under \\
\hline 18 & 5 & 7 & Under \\
\hline 19 & 3 & 1 & Over \\
\hline 20 & 1 & 7 & Under \\
\hline
\end{tabular}


Mean Attribution Scores for Pre - Task Estimations

Compared to Demonstrated Performance Scores on the Task: Organizing Your Day

Predicted Pre - Task Questionnaire scores among the individuals in the schizophrenic group ranged from zero to eight. The median Pre - Task prediction score was three, and the mean Pre - Task estimated score was 2.75. The standard deviation from the mean estimated score was 2.17. Scores on the Task: Organizing Your Day ranged from zero to eight. The median score was 5 , and the mean score was 4.5 and the standard deviation from the mean was 2.8). A Student's T-test was used to determine the statistical difference between mean scores of the Pre - Task Estimations and the scores on the Task: Organizing Your Day. The difference in mean Pre - Task estimations versus the mean of the demonstrated scores on the Task: Organizing Your Day was significantly different ( $p$ value $<0.001,19$ degrees of freedom; See Table 5).

Post - Task Questionnaire Estimations Compared to Demonstrated Performance Scores on the Task: Organizing Your Day

On the Post - Task Questionnaire respondents could; (a) score strongly agree or somewhat agree that yes, they were able to schedule to complete errands and attend all appointments; (b) strongly disagree or somewhat disagree that no, they were not able to schedule to complete errands and attend all appointments; (c) score neutral, they were unable to agree or disagree if they were able to schedule to complete errands and attend all appointments.

Twenty-five percent of the respondents' estimates on the Post - Task questionnaire were accurate when compared to demonstrated performance on the Task: Organizing Your Day. Fifty percent of the respondents' scores on the Post - Task questionnaire overestimated their performance on the Task: Organizing Your Day. The remaining $25 \%$ of the respondents were unable to score estimates on the Post - Task questionnaire. 
Table 5

Mean Attribution Scores for Pre - Task Estimations Compared to Demonstrated

Scores on the Task: Organizing Your Day $(\mathrm{N}=20)$

\begin{tabular}{l} 
Condition Pre - Task Estimations a Task scoreb \\
\hline M \\
SD" \\
Note. The values represent mean percentages of the estimated number of tasks \\
that could be scheduled, and the demonstrated number of tasks scheduled. \\
Range of scores $0-8$. \\
a Estimation $=$ the number of tasks the respondent scored somewhat disagree or \\
strongly disagree as possibly troublesome. \\
b Score = the number of tasks the respondent was able to schedule \\
while adhering to task directions.
\end{tabular}


Of the five respondents who accurately estimated their performance on the Post - Task questionnaire, two respondents completed all eight tasks (a perfect score) and marked strongly agree indicating that they were able to schedule to complete errands and attend all appointments. Two respondents completed five tasks and marked somewhat disagree that they were able to schedule to complete all tasks and errands.

One respondent completed six tasks, and marked strongly disagree indicating that he had scheduled to complete all errands and attend all appointments. The latter three respondents accurately estimated they were unable to schedule to complete errands and attend all appointments (See Table 6).

\section{Responses to Open-Ended Questions}

Pre - Task Questionnaire

The Pre - Task research questionnaire asked respondents to give written responses to the following question: "if you have problems getting everything done each day, what kind of problems do you have?" Of the 20 individuals with schizophrenia who participated in the study, 12 responded to this question. Three individuals gave multiple responses to the question.

Based on the respondents' clusters of similar answers, three major themes emerged to explain why the respondents were unable to complete daily tasks. They were: motivation or lack of motivation, external influences, and self-care activities.

The most frequent reason given by this sample for not making a schedule within this sample was lack of motivation. Ten of the respondents reported that this internal factor interfered with their ability to get things done each day. Two respondents stated "lack of energy"; three wrote "trouble getting motivated"; two wrote simply "getting out of bed" was a problem; one reported "lack of will and incentive"; one found it "hard waking up"; and one wrote " (the) need to fight off paranoia" as reasons for inability to complete daily tasks. 
Table 6

Comparison of Demonstrated Task Performance and Post - Task Estimations $(\underline{N}=20)$

\begin{tabular}{|c|c|c|c|}
\hline Respondents: & Task score & Post - Task Estimations ${ }^{b}$ & OverNnder/Neutralc \\
\hline 1 & 5 & SA & Over \\
\hline 2 & 1 & SA & Over \\
\hline 3 & 6 & SA & Over \\
\hline 4 & 6 & SA & Over \\
\hline 5 & 0 & $\mathbf{N}$ & Neutral \\
\hline 6 & 8 & SA & Accurate \\
\hline 7 & 8 & SA & Accurate \\
\hline 8 & 6 & SD & Accurate \\
\hline 9 & 5 & $\mathbf{N}$ & Neutral \\
\hline 10 & 5 & SWD & Accurate \\
\hline 11 & 7 & $\mathbf{N}$ & Neutral \\
\hline 12 & 2 & SA & Over \\
\hline 13 & 5 & SA & Over \\
\hline 14 & 0 & $\mathbf{N}$ & Neutral \\
\hline 15 & 0 & $\mathbf{N}$ & Neutral \\
\hline 16 & 7 & SA & Over \\
\hline 17 & 5 & SWD & Accurate \\
\hline 18 & 7 & SA & Over \\
\hline 19 & 1 & SWA & Over \\
\hline 20 & 7 & SA & Over \\
\hline
\end{tabular}

Key: Strongly Agree $=S A ;$ Somewhat Agree $=S W A ;$ Neutral $=N$; Somewhat Disagree $=$ SWD;

Strongly Disagree $=$ SD

Note. Responses to question 4 of the Post - Task Questionnaire "Were you able to complete your errands and attend all of your appointments?"

a Number of tasks the respondent scheduled while adhering to task directions.

${ }^{b}$ Responses to question 4 of the Post - Task Questionnaire "Were you able to complete your errands and attend all of your appointments?

${ }^{c}$ Estimation compared to task performance score. 
The next most frequent reason given for inability to get things done each day focused on external influences or factors. Two of the 12 respondents reported that "finding transportation" and "taking the bus to make it to appointments" were problems. Two individuals stated that "lack of money" was a major problem.

The final reason given for not being able to complete daily tasks focused on selfcare activities. Three of the respondents stated that self-care activities interfered with their ability to get things done each day. One reported that "taking a shower, and shaving" and "dressing" was difficult, and the second individual stated "getting out of the house" interfered with getting things done each day, and one respondent reported "time management is bad, can't get chores done."

\section{Post - Task Questionnaire}

To the question "if you could not complete your errands and attend your appointments, what happened?", eight of 20 individuals responded. Based on the respondents' clusters of similar answers, three major themes emerged explaining why the respondents were unable to complete the tasks included in the Task: Organizing Your Day. The three themes that emerged were self-care activities, physical complaints and negative self-talk. There were three responses for self-care activities and physical complaints.

Three individuals reported that activities of daily living (ADL) interfered with their ability to complete the schedule-making task. One respondent stated that "going to the bathroom, getting dressed, and making the bed" interfered, one respondent reported that he needed to "take medications and eat" during the day, and one respondent wrote that he had to "go to group."

Three respondents reported that physical complaints interfered with their abilities to complete the Task: Organizing Your Day. Of these three respondents, one wrote he was "feeling ill"; one stated she was "having low blood sugar and I'm tired"; and the third 
respondent reported "my head hurts and I'm dizzy."

The next most frequent reason given for not completing tasks and errands was negative self-talk. Two remaining respondents stated, "I feel bad" and "I feel stupid" in regard to not completing the task, but did not elaborate further.

Pre - Task and Post - Task Questionnaire Responses Not Addressed in Study

There were a total of five questions asked on the Pre - Task Questionnaire. Questions (1) and (2) were used to select out those respondents who had eyesight problems that would interfere with participating in the study. All of the respondents in the study responded no to these questions. Data for questions (3) and (4) were not reported in the research report. The Post - Task Questionnaire included a total of five questions. Data for questions (1) (2) and (3) were not reported in this research report.

\section{Research Questions Answered}

The research questions generated for the study were:

1) To what degree were individuals with schizophrenia able to estimate their performance Pre - Task?

Eighty-five percent of the respondents (17) were inaccurate in their prediction of their performance Pre - Task, while fifteen percent or three respondents were accurate. Fifteen percent or three respondents overestimated their ability on the Pre - Task Questionnaire, $15 \%$ or three respondents accurately estimated ability on the Pre - Task Questionnaire, and $70 \%$ or 14 respondents underestimated ability on Pre - Task performance.

2) If Pre - Task estimations differ from task results, do individuals with schizophrenia overestimate or underestimate their abilities?

The Pre - Task estimations differed significantly from task results at $\mathrm{p}<.001$. Seventy percent or 14 respondents underestimated performance, $15 \%$ or three respondents accurately predicted their performance (zero estimated and achieved score 
on zero) and $15 \%$ or three respondents overestimated performance. The mean selfpredicted score in the schizophrenic group was 2.75 (standard deviation $=2.17$ ). The mean demonstrated score in the schizophrenic group was 4.75 (standard deviation = 2.67) (See Table 6).

3) To what degree are individuals with schizophrenia able to estimate their performance Post - Task?

Seventy-five percent of the respondents were inaccurate in estimating their performance Post - Task. Twenty-five percent or five respondents estimated performance Post - Task accurately. Fifty percent or 10 respondents overestimated their performance Post - Task. The remaining $25 \%$ or five respondents were unable to estimate performance Post - Task. These five respondents' responses were neutral. For a comparison of Pre - Task estimations and Post - Task estimations to performance scores on the Task: Organizing Your Day, See Table 7. 
Table 7

Comparison of Pre - Task Estimations and Post - Task

Estimations to Demonstrated Task Performance $(\underline{N}=20)$

\begin{tabular}{|c|c|c|c|}
\hline Subjects: & Pre - Task Estimations & Task score & Post - Task Estimations \\
\hline 1 & Under & 5 & Over \\
\hline 2 & Over & 1 & Over \\
\hline 3 & Under & 6 & Over \\
\hline 4 & Under & 6 & Over \\
\hline 5 & Accurate & 0 & Neutral \\
\hline 6 & Under & 8 & Accurate \\
\hline 7 & Under & 8 & Accurale \\
\hline 8 & Under & 6 & Accurate \\
\hline 9 & Under & 5 & Neutral \\
\hline 10 & Under & 5 & Accurate \\
\hline 11 & Over & 7 & Neutral \\
\hline 12 & Over & 2 & Over \\
\hline 13 & Under & 5 & Over \\
\hline 14 & Accurate & 0 & Neutral \\
\hline 15 & Accurate & 0 & Neutral \\
\hline 16 & Under & 7 & Over \\
\hline 17 & Under & 5 & Accurate \\
\hline 18 & Under & 7 & Over \\
\hline 19 & Over & 1 & Over \\
\hline 20 & Under & 7 & Over \\
\hline
\end{tabular}




\section{CHAPTER 5}

\section{DISCUSSION, RECOMMENDATIONS AND SUMMARY}

Discussion

\section{Underestimation of Pre - Task Performance}

There was a significant difference between Pre - Task estimations and scores for the Task: Organizing Your Day in $85 \%$ of the respondents with schizophrenia. The respondents' perceptions, measured by self-report, were inaccurate regarding their ability to estimate task performance. The respondents with schizophrenia had a tendency to underestimate their problem-solving abilities by a margin of 2.0 tasks. The mean score of this group indicated a tendency to estimate Pre -Task performance at 2.75, while the mean score indicating ability to schedule was 4.75 tasks on Organizing Your Day. Based on the data collected, the research suggests that persons with schizophrenia have a tendency to underestimate their problem-solving abilities associated with scheduling activities of daily living.

Information processing involved in problem-solving can be motivated by external stimuli, or it can be driven by internal expectations and prior experiences or a combination that interacts. An individual's motivation and emotional state will influence the extent to which information is processed deeply and monitored (Bandura, 1988). Metacognitive skills, the ability to predict results, and estimate task difficulty are related to motivation. If a person inaccurately anticipates the consequences of his or her actions due to inferior insight, one may perceive that he or she has no control over his or her performance and subsequently feel that an external locus of control exists (Kielhofner \& Burke, 1985; Toglia in Katz, 1992). Perhaps internalized lack of motivation is a contributing factor to 
respondents' general low self-estimation of their problem-solving skills and abilities Pre - Task. Toglia stated that the inability to accurately evaluate task difficulty in relation to oneself and to predict performance outcomes can create a perceived loss of control that can increase anxiety, decrease motivation, and further impede the learning process (Toglia, 1989a).

The data collected in this study adds support to this literature. Of the 12 respondents who responded to the open ended question on the Pre - Task Questionnaire "if you have problems getting everything done each day, what kind of problems do you have?", 10 or $80 \%$ stated that lack of motivation was a contributing factor.

Inaccurate Estimation of Post - Task Performance

Seventy-five percent of the respondents studied were inaccurate at estimating performance Post - Task. The research question asked "to what degree are individuals with schizophrenia able to estimate their performance Post - Task?" Post - Task estimations were compared to task scores as well, and interpreted descriptively. Of the 20 respondents with schizophrenia, there was a difference observed between Post -Task estimation of scores and demonstrated task scores in $70 \%$ of the cases.

Twenty-five percent of the respondents accurately estimated performance Post - Task. Fifty percent of the respondents overestimated their performance Post - Task. The remaining $25 \%$ of the respondents were unable to estimate their performance Post - Task.

An interesting observation was made that seven of the 10 respondents who overestimated their performance Post - Task underestimated their performance Pre - Task. Three of the 10 remaining respondents who overestimated performance Post - Task, also overestimated performance Pre - Task.

The schizophrenic individual's tendency to overestimate performance Post - Task 
in contrast to their tendency to underestimate performance Pre - Task, was an unexpected discovery of the study. A possible explanation for the respondents' tendency to overestimate performance Post - Task is offered by the dynamic interactional literature. As noted earlier, metacognition refers to awareness and control of one's own thinking skills (Flavell, 1985). Two interrelated aspects of metacognition include (a) knowledge concerning one's own cognitive processes and capacities and, (b) the ability to monitor one's own performance. The 10 individuals who overestimated their performance Post - Task demonstrated decreased awareness of their own cognitive processes, and exhibited deficits in their ability to employ the metacognitive skill of self-monitoring to evaluate their task performance. This statement may partially explain why 10 individuals overestimated Post - Task performance.

Conversely, problem-solving may not proceed if the person feels unable to cope with the situation (Bellack, Morrison, \& Mueser, 1989). The latter statement may pertain to the $25 \%$ of respondents who possibly felt overwhelmed by the questionnaire and were incapable of estimating Post - Task performance.

According to Toglia and Golisz, (1990), an individual who exhibits poor problemsolving skills may be unable to prioritize which steps need to be taken in a stepwise progression, or may be unable to break the task into steps. Excessive time may be spent processing nonessential details. These respondents were also exhibiting rigidity of thought, a characteristic of schizophrenia. Rigidity of thought results in limited ability of the schizophrenic to devise alternative solutions to problems. Findings of this research support the previous statements. Of the eight respondents who answered the open ended question on the Post - Task Questionnaire if you could not complete your errands and attend your appointments, what happened?", three respondents (or $40 \%$ ) reasoned self ADL interfered with ability to complete all tasks. 
Pre - Task Estimations of a Schizophrenic Group Vs. a Brain-Iniured Group

Interestingly, the results of this study both parallel and contrast the findings of a study of brain-ikijured individuals found in the literature. Research investigating metacognitive deficits of individuals with brain-injury suggests that a large number of adults were inaccurate in estimating pre and post task difficulty, and had a tendency to overestimate their abilities or underestimate the severity of their deficits (Anderson \& Tranel, 1989; Toglia, 1989a). Anderson and Tranel, (1989) used a standardized interview to measure unawareness and found that $72 \%$ of patients with stroke and $68 \%$ of patients with head trauma demonstrated poor insight concerning their cognitive functioning. Insight or the degree of awareness one has regarding one's cognitive or physical capacities, is often impaired in adults with brain injury. It has been demonstrated that there is a greater incidence of unawareness in patients with frontal lobe injury or right hemisphere damage, but this phenomenon is still poorly understood (Anderson \& Tranel, 1989; McGlynn \& Schacter, 1989).

The above-mentioned study of brain-injured adults contrasts with the findings of this study. Individuals with schizophrenia had a tendency to underestimate their abilities on the Pre - Task questionnaire prior to performing the Task: Organizing Your Day. These respondents underestimated their abilities prior to the task, or overestimated their own cognitive deficits. Task performance of individuals with schizophrenia surpassed Pre - Task estimations by a margin of two tasks.

Interestingly, this study found that while individuals with schizophrenia had a tendency to underestimate their ability Pre - Task, they had a tendency to overestimate their performance Post - Task when compared to their task performance. This overestimation of performance Post - Task parallels the research investigating metacognitive deficits of individuals with brain-injury. Research found in the literature 
suggests that a large number of brain-injured adults were inaccurate in estimating task difficulty, and had a tendency to overestimate their abilities or underestimate the severity of their deficits (Anderson \& Tranel, 1989; Toglia,1989a). Those patients with head trauma demonstrated poor insight concerning their cognitive functioning. These unexpected findings of schizophrenic individuals' Post-Task overestimation of abilities warrant further research.

Implications for Treatment

Studies have shown that brain-injured individuals are inaccurate in estimating task difficulty. This study found schizophrenic individuals to have a tendency to underestimate their abilities Pre - Task. It is important for the clinician to understand this distinction, and formulate a different treatment plan for the schizophrenic patient. A schizophrenic individual who has a tendency to underestimate his or her own problem-solving abilities may encounter a non-therapeutic interaction between the clinician and the patient when low expectations are either (a) imposed upon the patient by the inexperienced occupational therapist or (b) the patient does not believe he or she can surpass his or her own low anticipated goals.

Instead of attempting to teach the patient compensatory strategies, it is suggested by the dynamic interactional literature that treatment directly address the problem of awareness. Modification of a patient's perception concerning his or her own problems may significantly affect the subsequent course of treatment (Cicerone \& Tupper, 1986). Examples of awareness techniques include self-estimation and self-evaluation and role reversal, and can be integrated into functional activities such as dressing or cooking, as well as tabletop activities (McGlynn \& Schacter, 1989; Toglia \& Golisz, 1990).

Self-estimation, a metacognitive skill, involves asking the patient to estimate his or her performance before, during or immediately after completing a task. The patient's self- 
assessment is compared with the actual results to help the patient evaluate his or her performance. When the patient can accurately assess his or her performance, he or she is then asked to predict his or her performance before performing a task. The patient's original prediction is compared with his or her actual performance. The objective is to increase the accuracy of predictions so that they can become more realistic.

Self-evaluation involves having the patient fill out a self-evaluation form after a task is completed to help him or her accurately assess outcome. Questions might include, "Have I checked all my work carefully?" "Have I paid attention to all the details?" or "How confident do I feel with my results? ${ }^{n}$

Role reversal is a technique by which the patient observes a therapist performing a task. The therapist makes errors and the patient must identify the errors and hypothesize why the errors occurred. For example, the patient may observe that the therapist went too fast or did not pay attention to details. The goal of role reversal is to increase error detection and increase the patient's analysis skills (Ben-Yishay \& Diller, 1983b).

Treatment techniques that aim to help the patient detect errors, predict outcomes, estimate task difficulty and evaluate performance outcome are suggested to increase insight and self-monitoring skills (Ben-Yishay \& Diller, 1983b; Cicerone \& Wood, 1987; Lawson \& Rice, 1989; McGlynn \& Schacter, 1989; Pollens, McBratnie, \& Burton, 1988).

Recommendations

Improvements for Questionnaire

The questionnaire, designed by the researcher, requires further refinement. Suggestions include shortening the questionnaire and simplifying the answer choices to yes, no and unsure. Reliability and validity need to be assessed. The open-ended questions should be more fully developed with probe questions. The Post-Task 
Questionnaire did not ask the respondents to give a numerical value of estimated Post - Task performance. For this reason no numerical statistics could be compared between task performance and estimated Pre - Task performance. This factor was a limitation of the study.

The Post - Task estimation questionnaire should ask the respondents to estimate the total number of tasks they completed from the Task: Organizing Your Day. This would enable the researcher to compare Pre - Task estimation scores, with task performance scores, with Post -Task estimation scores.

\section{Future Research}

This pilot study was exploratory and appears to demonstrate that differences exist between a schizophrenic patient's perception of performance, and his or her actual performance involving problem-solving skills. Future research should be directed at studying a larger population of schizophrenic patients and replicating this study.

In addition, it would be interesting to administer a revised questionnaire to a pilotstudy population of brain-injured, normal functioning adults, and schizophrenic individuals to compare perception of performance with demonstrated performance.

Data for questions not addressed in this research report should be analyzed to compare respondents' answers to Post - Task question (1) 'How hard was this task for you?" and their estimation of performance Post - Task and task performance.

\section{Summary}

The findings of this study showed that individuals with schizophrenia inaccurately estimate their ability to accomplish a problem-solving task. The respondents' perceptions, measured by self-report, were inaccurate regarding their ability to estimate performance Pre - Task. Pre - Task estimations compared to task performance resulted in an overall $85 \%$ inaccuracy rate. Fifteen percent accurately predicted Pre - Task ability, 
$15 \%$ overestimated Pre - Task ability, and the remaining $70 \%$ underestimated performance Pre - Task in relation to task performance.

The respondents' perceptions, measured by self-report, were inaccurate regarding their ability to estimate performance Post - Task. Post - Task perception of performance compared to task performance resulted in an overall $75 \%$ inaccuracy rate. Twenty-five percent of the respondents estimated performance Post - Task accurately. Fifty percent of the respondents overestimated their performance Post - Task. The remaining $25 \%$ of the respondents were unable to estimate performance Post - Task. These five respondents' responses were neutral concerning performance Post - Task.

Interestingly, schizophrenic individuals' perceptions of their abilities measured Pre - Task was generally lower than their actual task performance. However, individuals with schizophrenia also had a tendency to overestimate their performance Post - Task when compared to task performance. After completing the problem-solving task, a schizophrenic individual's perceptions of his or her abilities were generally higher than his or her actual task performance.

This study demonstrates the inability of the individual with schizophrenia to accurately estimate his or her own abilities, both prior to a task and following a task involving problem-solving in schedule-making. This is the first study to explore this phenomenon in individuals with schizophrenia. The results of this study provided baseline information of respondents with schizophrenic tendencies to underestimate performance Pre - Task and overestimate performance Post - Task. This interesting area of study needs further investigation. 


\section{References}

Abreu, B. C. \& Toglia, J. P. (1987). Cognitive rehabilitation: A model for occupational therapy. American Joumal of Qccupational Therapy, 41, 439-448.

Allen, C. K. (1985). Occupational therapy for psychiatric disease: Measurement and management of cognitive disabilities. Boston: Little, Brown and Co.

Allen, C. K. (1987). Activity: Occupational therapy's treatment method. American Joumal of Occupational Therapy, 41, 563-576.

Allen, C. K. (1988). Occupational therapy: Functional assessment of the severity of mental disorders. Hospital Community Psychiatry, 39, 140-142.

Amador, X., Strauss, D., Yale, S., \& Gorma, J. (1991). Awareness of illness in schizophrenia. Schizophrenia Bulletin, 17, 113-128.

American Psychiatric Association (1987). Diagnostic and statistical manual of mental disorders, DSM-1IR. Washington DC: Author.

Anderson, S. W., \& Tranel, D. (1989). Awareness of disease states following cerebral infarction, dementia, and head trauma: Standardized assessment. Clinical Neuropsychologist, 3, 327-339.

Bandura, A. (1988). Social foundations of thought and action: A social cognitive theon. Englewood Cliffs, NJ: Prentice Hall.

Bellack, A. S., Morrison, R. L., \& Mueser, K. T. (1989). Social problem solving in schizophrenia. Schizophrenia Bulletin, 15 (1), 101-116.

Belmont J., Butterfield, E. C., \& Ferretti, R. P. (1982). To secure transfer of training: Instruct self-management skills. In D. K. Detterman and R. J. Stemberg (Eds.), How and how much can intelligence be increased. Norwood, NJ: Ablex.

Ben-Yishay, Y. \& Diller, L. (1983). Cognitive remediation. In M. Rosenthal, E. Griffith, M. Bond, \& J. Miller (Eds.), Behabilitation of the head iniured adult (pp. 367-391). Philadelphia: F. A. Davis Co.

Bleuler, E. (1983). Lehnudch der Psychiatrie. Berlin, West Germany: Springer.

Bransford, J., Shenwood, R., Vye, N., \& Rieser, J. (1986). Teaching thinking and problem solving: Research foundations. American Psychologist, 41, 1078-1089.

Brown, A. (1988). Motivation to learn and understand: On taking charge of one's own learning. Coonition and instruction, 5, 311-321.

Carpenter, W. T., Strauss, J. S., \& Bartdo, J. J. (1973). Flexible system for the diagnosis of schizophrenia; Report from the WHO pilot study of schizophrenia. Science, 182, $1275-1278$.

Christiansen, C. (1992). Theory in occupational therapy. In C. Christiansen \& C. Baum (Eds.), Occupational therapy: Overcoming human deficits (pp. 411-418). New York: Slack Incomporated. 
Cicerone, K. D., \& Wood, J. C. (1987). Planning disorder after closed head injury: A case study. Archives of Physical Medicine and Rehabilitation, $\underline{68}, 111-115$.

Crow, T. J. (1985). The two-syndrome concept: Origins and current status. Schizophrenia Bulletin, 11, 475-485.

Cuesta, M. J., \& Peralta, V. (1994). Lack of insight in schizophrenia. Schizophrenia Bulletin, 20, 359-366.

Depoy, E. \& Kolodner, E. (1992). Psychological performance factorS. In C. Christiansen \& C. Baum (Eds.), Occupational therapy: Overcoming human deficits (pp. 310-325). New York: Slack Incorporated.

Duchek, J. (1992). Cognitive dimensions of performance. In C. Christiansen \& C. Baum (Eds.), Occupational therapy: Overcoming human deficits (pp. 286-289). New York: Slack incorporated.

Feuerstein, R. (1979). The dynamic assessment of retarded performers: The learning potential device, theory, instruments and techniques. Baltimore: University Park Press.

Fine, S. B. (1992). Applying cognitive rehabilitation to mental health. Tucson, AZ: Therapy Skill Builders. Inc.

Flavell, J. H. (1985). Cognitive development. Englewood Cliffs, NJ: Prentice Hall

Goldstein, G. (1986). The neuropsychology of schizophrenia. In J. Grant and K. M. Adams (Eds.), Neuropsychological Assessment of Neuropsychiatric Disorders (pp. 147-171). New York: Oxford University Press.

Hogarty, G. E. (1985, October). Treatment resistance of schizophrenic patients to social and vocational rehabilitation: the nature of the problem and model of treatment. Presentation at International Symposium of Schizophrenia. Munich, Germany.

Katz, N. (1992) Introduction. In N. Katz (Ed.), Cognitive rehabilitation: Models for intervention in occupational therapy (pp. 15-25). Boston, MA: Andover Medical Publishers.

Keith, D. S., (1988). Aftercare of psychiatric patients and its relation to hospitalization. Hospital and Community P sychiatry, 28, 118-121.

Kielhofner, G. \& Burke, J. P. (1985). Components and determinants of human occupation. In G. Kielhofner, A model of human occupation: Theory and application (pp. 12-36). Baltimore: Williams and Wilkins.

Lawson, M. J., \& Rice, D. N. (1989). Effects of training in use of executive strategies on a verbal memory problem resulting from closed head injury. Joumal of Clinical and Experimental Neuropsychology, 11, 842-854.

Levine, D. J., \& Brayley, L. D. (1992) Systems theory approach. In C. Christiansen \& C. Baum (Eds.), Occupational therapy: Overcoming human deficits (pp. 198-216). New York: Slack Incorporated. 
$62-84$.

Liberman, R. P. (1982). Assessment of social skills. Schizophrenia Bulletin $\underline{8}$ (1),

McGlynn, S. \& Kaszniak, A. (1991). Unawareness of deficits in dementia and schizophrenia. In Prigatano, G., \& Schacter, D. (Eds.), Awareness of deficit after brain injury, (pp. 84-110). New York: Oxford University Press.

McGlynn, S. \& Schacter, D. (1989). Unawareness of deficits in neuropsychological syndromes. Joumal of Clinical and Experimental Neuropsychology 11 , 143-205.

York: Raven.

Mosey, A. C. (1986). Psychosocial components of occupational therapy. New

Pedretti, L. W. (1990). Occupational therapy practice skills for physical dysfunction, (3rd ed.) ST. Louis: C.V. Mosby.

Piaget, J. (1954). The construction of reality in the child. New York: Basic Books.

Pollens, A., McBratnie, B., \& Burton, P. (1988). Beyond cognition: Executive functions in closed head injury. Cognitive Rehabilitation, $\underline{6}, 26-31$.

Prigatano, G. (1991). Disturbances of self-awareness of deficit after traumatic brain injury. In Prigatano, G. \& Schacter, D. (Eds.), Awareness of deficit after brain injury, (pp.111-126). New York: Oxford University Press.

Seron, X. \& Deloche, G. (1989). introduction. In X. Seron \& G. Deloche (Eds.), Cognitive approaches in neuropsychological rehabilitation, (pp. 1-15). Hillsdale, NJ: Lawrence Erlbaum Associates. Incorporated.

Serrett, K. D. (1985). Occupational therapy history. Thorofare, NJ: Slack

Toglia, J.P. (1989a). Approaches to cognitive assessment of the brain- injured adult: Traditional methods and dynamic investigation. Occupational Therapy Practice, 1. 36-57.

Toglia, J. P. \& Fine, S. B. (1990, November). Applying cognitive rehabilitation to mental health: Assessment and treatment strategies for schizophrenia. (Supplement handouts to workshop conducted at New York Hospital-Cornell Medical Center, New York).

Toglia, J. P. \& Golisz, K. (1990). Cognitive rehabilitation: Group games and activities. Tucson, AZ: Therapy skill builders.

Toglia, J. P. (1991). Generalization in treatment: A multicontextual approach to cognitive perceptual impairment in the brain injured adult. American Journal of Occupational Therapy, 45 , 505-516.

Toglia, J. P. (1992). A dynamic interactional approach to cognitive rehabilitation. In N. Katz (Ed.), Cognitive rehabilitation: Models for intervention in occupational therapy (pp. 104-143). Boston, MA: Andover Medical Publishers. 
Toglia, J. P. (personal communication. October 15, 1993).

Toglia, J. P. (personal communication. June 19, 1995).

Trexler, L. (1987). Neuropsychological rehabilitation in the United States. In M. Meier, A. Benton, \& L. Diller (Eds.), Neuropsychological rehabilitation (pp. 437-460). New York: Guilford Press.

Vygotsky, L. S. (1978). Mind in society: The development of higher psychological processes. Cambridge, MA: Harvard University Press. 
Appendix A

\section{Organizing Your Day}

and

Worksheet 


\section{ORGANIZING YOUR DAY}

You have a busy day ahead. You have a doctor's appointment. You must also go to the gift shop to buy a birthday card for your friend Bill's birthday party, go to the post office to mail an important package, to the bank to get enough money (you have to pay cash for everything today), order and pick up a special ice cream cake for Bill's birthday, pick up a prescription from the drug store, and meet your friend Mary for lunch.

It is now 10:00 AM. Bill's birthday party starts at 8:00 PM. All the stores and offices are open. The post office, bakery, gift shop and drugstore close at 5:00 PM. The bank closes at 3:00 PM. Your doctor's appointment is at 2:00 PM. Mary can meet you any time.

It is a beautiful sunny day and you decide to walk. Here is a map that shows where everything is located. All the buildings are located 20 minutes away from each other.

Bakery

Bank

Drugstore
You live here

Restaurant

\section{Doctor's Office}

Bill's House
Gift Shop

\section{Post Office}

You are ready to leave now. How will you arrange your schedule so you can do everything you want? There is more than one way to schedule your day. Which seems best to you? 
Appendix B

Pre-Task Questionnaire 


\section{Pre-Task Questionnaire}

\section{Estimation of Performance Prior to Task}

1) Do you have any problems with your eyesight?

Yes No Unsure

2) If so what are they?

3) Do you agree or disagree with the following statement:lt is hard for me to organize daily activities. Strongly Disagree Somewhat Disagree Neutral Somewhat Agree Strongly Agree

$\begin{array}{lllll}1 & 2 & 3 & 4 & 5\end{array}$

4) If I ask you to perform a task that invoives problem-solving, do you think you would have any trouble with it?

Strongly Disagree Somewhat Disagree Neutral Somewhat Agree Strongly Agree

$\begin{array}{lllll}1 & 2 & 3 & 4 & 5\end{array}$

5) Do you agree or disagree you will have any difficulty making a daily schedule for yourself if you had:

\begin{tabular}{|c|c|c|c|c|c|}
\hline One thing to do: & $\underline{\text { Strongly Disagree }}$ & Somewhat Disagree & Neutral & Somewhat Agree & Strongly Agree \\
\hline & 1 & 2 & 3 & 4 & 5 \\
\hline Two things to do: & Strongly Disagree & Somewhat Disagree & Neutral & Somewhat Agree & Strongly Agree \\
\hline & 1 & 2 & 3 & 4 & 5 \\
\hline Three things to do: & Strongly Disagree & Somenthat Disagree & Neutral & Somenthat Agree & Stronglv Agree \\
\hline & 1 & 2 & 3 & 4 & 5 \\
\hline Four things to do: & Strongly Disagree & Somentat Disagree & Neutral & Somentiat Agree & Strongly Agree \\
\hline & 1 & 2 & 3 & 4 & 5 \\
\hline Five things to do: & Strongly Disagree & $\underline{\text { Somewhat Disagree }}$ & Neutral & Somewhat Agree & Strongly Agree \\
\hline & 1 & 2 & 3 & 4 & 5 \\
\hline Six things to do: & Strongly Disaqree & Somenhat Disagree & Neutral & Somewhat Agree & Strongiy Agree \\
\hline & 1 & 2 & 3 & 4 & 5 \\
\hline Seven things to do: & $\underline{\text { Strongly Disagree }}$ & Somewhat Disagree & Neutral & Somenhat Agree & Strongly Agree \\
\hline & 1 & 2 & 3 & 4 & 5 \\
\hline Eight things to do: & Strongly Disagree & $\underline{\text { Somewhat Disagree }}$ & Neutral & Somewhat Agree & Strongly Agree \\
\hline & 1 & 2 & 3 & 4 & 5 \\
\hline
\end{tabular}

6. If you have problems getting everything done each day, what kind of problems do you have? 
Appendix C

Post-Task Questionnaire 


\section{Post-Task Questionnaire \\ Estimation of Performance After Completion of Task}

1. How hard was this task for you?

Very Easy Somewhat Easy Not Sure Somewhat Difficult Very Difficult

$\begin{array}{llll}2 & 1 & 3 & 5\end{array}$

2. How hard was it for you to make a schedule for yourself?
\[ \underline{\text { Very Easy }} \text { Somewhat Easy Not Sure Somewhat Difficult Very Difficult } \]

3. Do you think this schedule you made was the best schedule that could be made?

Strongly Disagree Somewhat Disagree Neutral Somewhat Agree Strongly Agree

4. Do you agree or disagree you able to complete your errands and attend all of your appointments?

Strongly Disagree Somewhat Disagree Neutral Somewhat Agree Strongly Agree

5. If you could not complete your errands and attend your appointments, what 5 happened? 
Appendix D

Consent Form 
Colloge of Applied Sclences and Arts - Depurtment of Occupational Therapy

One Washington Square - San José, Calltornia 95192-0059

Main Otlice: 408/924-3070 • Fieldwork Otfico: 408/924-3078 - FAX: 408/924-3088

CONSENT TO BE A RESEARCH SUBJECT

Research Project:

Delicits Experienced by Persons With Chronic Schizophrenia Pnnciple Investigator Jennifer C. Chapman (Occupational therapy graduate student)

The researcher is interested in studying the relationship between deficits and problem solving prosessing strategies as experienced by persons with schizophrenia. Should you decide 10 participate in the study, you will be asked to estimate your problem solving abilities. You will be asked to read a paragraph and complete answers that require problem solving. Following the task. you will be asked a few questions about your pertonnance on the task. Your participation should last less than one (1)hour and will be arranged at a time that is convenient for you. You will meet with the researcher at CPC Heritage Oaks Hospital

The information gained from your participation in the study will be used to increase occupational therapists' knowedge of problem solving and cognitive disability in the schizophrenic population. It will be used to facilitate appropriate assessment and enhance treatment benefits to these individuals. Your privacy will be protected as fat as is possible under the law. and your name will not appear on any of the research information.

Participation in research is voluntary and choosing not to participate in this siudy. will not affect your relations to the hospital. You are free to withdraw your consent and discontinue your participation in this study at any time.

You will not receive any special compensation for your participation. If you have any questions about this study. I will be happy to talk with you. I can be reached at (408) 924-3070. If you have questions or complaints about research subject's rights, or in the event of a research related injury, please contact Serena Stantord. Ph.D.. Associate Academic Vice President for Graduate Studies and Research. at (408) 924-2480.

Sincerely.

Jenniter C. Chapman

Signalure 
Appendix $E$

Facility Consent for Participation 


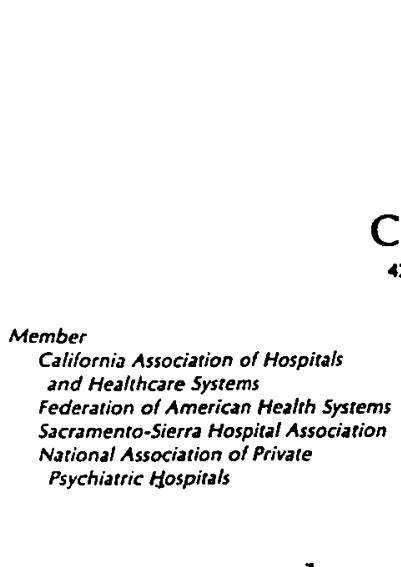

February 3, 1994

To Whom It May Concern:

I have read the research proposal as drafted by Jennifer Champan, occupational therapy graduate student, entitled Self-Estimation of Problem Solving Skills of Person with Schizophrenia. This letter serves to inform you that the protocol was approved during the general medical staff meeting staff meeting of October 31, 1993.

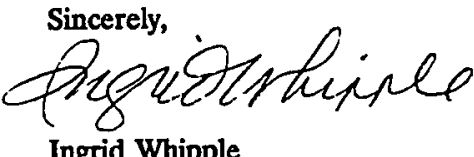

Chief Executive Officer

IW/tes 
Appendix $F$

Toglia's Orginal Organizing Your Day 
Functional Problem Solving Task

Organizing Your Day

1. You have a busy day ahead. You have a doctor's appointment. You must also go to the liquor store to buy wine for a party. fill-up the car with gas, go to ine post office to mail an important package. go to the bank to get enough money to pay the doctor's fee (he demands cash on visits). order and pick up a special ice cream cake for your friend's birthday, bring your prescription to the drug store. and meet a friend for lunch.

The post office, bakery. drugstore. liquor store all close at 5:00 p.m. The bank closes an 3:00 p.m. It is 10:00 a.m. now. Your doctor's appointment is at 2:00 p.m. At what time should you leave the house? Where will you go first. second. third. etc. 
Appendix $G$

Organizing Your Day Schedule and Worksheet 
Schedule

10:00 a.m.:

11:00 a.m:

12:00 p.m.:

1:00 p.m.:

2:00 p.m.:

3:00 p.m.:

4:00 p.m.:

5:00 p.m.:

6:00 p.m.:

7:00 p.m.:

8:00 p.m.: 